\title{
STRUCTURAL SUSTAINABILITY APPRAISAL IN BIM
}

\begin{abstract}
The provision of Application Programming Interface (API) in BIM-enable tools can contribute to facilitating BIM-related research. APIs are useful links for running plug-ins and external programmes but they are yet to be fully exploited in expanding the BIM scope. The modelling of n-Dimensional (nD) building performance measures can potentially benefit from BIM extension through API implementations. Sustainability is one such measure associated with buildings. For the structural engineer, recent design criteria have put great emphasis on the sustainability credentials as part of the traditional criteria of structural integrity, constructability and cost. This paper examines the utilization of API in BIM extension and presents a demonstration of an API application to embed sustainability issues into the appraisal process of structural conceptual design options in BIM. It concludes that API implementations are useful in expanding the BIM scope. Also, the approach including process modelling, algorithms and object-based instantiations demonstrated in the API implementation can be applicable to other $\mathrm{nD}$ building performance measures as may be relevant to the various professional platforms in the construction domain.
\end{abstract}

Keywords: API; BIM; conceptual design; nD modelling; structural design; sustainability appraisal

\section{Introduction}

Information modelling, design and management systems such as BIM are vital to the operation of Architecture, Engineering and Construction (AEC) industry. BIM is forecast as the next generation of Information Technology (IT) to replace drawing production-focused Computer Aided Drafting (CAD) and involves the processes of generating, storing, managing, exchanging and sharing of building information in an interoperable and reusable way [1]. Though BIM is still maturing and not yet fully defined in scope [2], its benefits in project implementation and information management are envisaged to be significant. As a digitized representation of the building artefact, BIM has the tendencies for continuous expansion to closely mimic the vast amount of information embedded in a typical building project. Such information, referred to as n-Dimensional (nD), include time, cost, accessibility, sustainability, maintainability, acoustic, crime, thermal requirements, health and safety etc. $[3,4]$. Modelling $\mathrm{nD}$ aspects such as sustainability require issue-specific approach and involve the extension of the building information model to incorporate the various building life cycle design information which are vast and cut across the various building professional platforms. The term extension in the context of this paper refers to new software systems that add additional functionality to BIM-enable tools through external applications relying on facilities such as Application Programming Interface (API). As such, the literature review of this paper discussed the investigation of API implementations in embedding applications in BIM-enabled environments as it is an essential part of the preliminary phase of this research. The review of algorithms and aspects on feature based modelling and information modelling have been covered elsewhere [5].

The existence of already operational proprietary BIM platforms presents a starting point for researchers to explore the possibilities of expanding the BIM scope to account for $\mathrm{nD}$ issues such as sustainability [6] and safety [7]; and customisation by other users. One of the software development kits available to use is API implementations. It can be adapted to different computer operating systems and has the benefit of allowing compiled codes to function without effecting any change to the system and the underlying codes that implements the API. Software vendors of BIM-enabled tools therefore have the benefit of making their products available for researchers and other users to develop prototypes to run as plug-ins. Such software platforms will serve as test-bed for Rapid Application Development (RAD) prototyping which can lead to the rapid increase in contributions to BIM expansion. However, research works taking advantage such facility in BIM implementation is yet to be fully explored. Taking advantage 
of API facility, the aim of this research is to investigate how the use of BIM technology can influence conceptual design decisions based on the life cycle information and the sustainability of alternative design solutions. This is targeted at quantifying the sustainability of design solutions to inform conceptual design decisions, as an integral part of BIM. This paper therefore examines the usefulness of API implementations and brings out how it can be used to tackle scope issues in BIM adoption. It present an example of an API implementation on using BIM to assess the sustainability measures of conceptual structural design options. The authors argue that it illustrates how process and data modelling techniques can be used to map and model sustainability related information to inform the structural engineer's building design decisions at an early stage.

The review of literature has been carried out to establish research challenges and study aspects relating to the API implementations and BIM-enabled systems in the construction domain. It also helped in identifying and adopting information modelling approaches such as the RAD approach [8] used in implementing a prototype based on a structural sustainability assessment framework. The RAD methodology employs cycles of re-specify, re-design and re-evaluate on the prototype system from its conception to when it achieves a high degree of fidelity and completeness. The prototyping process is therefore characterized by increased speed of development and experiences of series of births rather than deadlines. The implementation of the prototype involved the utilization of information modelling representations - in the form of a process model, implementation algorithms and object-based instantiations to capture sustainability related information to inform decisions at the early stages of the structural design process. The implementation took advantage of .NET Frameworks to explore existing links of interfacing of a BIM-enabled tool such as Revit Building Design Suit with programmes created in object oriented C\# programming language. This work has been carried on commercial BIM software due to its readiness in terms of required interface and availability. This is done in order to focus efforts on proving the feasibility of the API, which can later be translated to other BIM environments (such as open source BIM).

This paper features six sections. The Introduction (Section 1) is followed by the Literature review as Section 2 which discusses the investigation into BIM-related API applications and highlights the challenges with modelling sustainability decision support in BIM. Section 3 presents the conceptual sustainability modelling framework detailing its implementation process. An illustration of how the resulting prototype works is presented in Section 4. Section 5 discussed the relevance of the prototype and its limitations before concluding in Section 6.

\section{Literature Review}

This review provides an overview of API implementation, the use of API implementation to accomplish BIM extension and discusses the challenges with modelling sustainability decision support systems in BIM. API implementation in a BIM-enabled environment makes an essential part of this research and has been used as a vital tool in demonstrating the proposed research concept.

\subsection{API implementation overview}

API applications are not new in ICT related research. However, novel contributions can still be made in introducing suitable methodologies to accomplish new or upcoming research tasks. API generally specifies how different software components interact with each other which may involve access to database, hard drive, disc drive, video card etc. It is based on programming source codes (high-level interface) and includes a combination of specifications for programming language routines, data structures, classes and variables. This makes it different from Application Binary Interface (ABI) which is a low-level interface between computer programmes and operating systems. API has been found to be useful in various areas of software implementation. API specifications help to accomplish the presentation of functions and subroutines in human readable formats in procedural languages such as UNIX systems and Perl. In object oriented languages such as C\#, API helps to specify the interactions/handle by which objects, including their behaviours, are derived from their class definitions. The usefulness of API is also significant in the area of web development. The use of open architecture in web programming to dynamically share contents and data between communities and applications is actually an application of 
API technology. It is also possible to combine information from different web APIs to create a hybrid of new graphical interface, called mashups, with better visualisation and aggregation [9]. Lack of standardized APIs is identified as one the major challenges of the current evolution of the internet service delivery of cloud computing [10] which is currently being explored in distributed synchronous and asynchronous exchange/management of BIM data $[11,12]$. Cloud computing targets the provision of reliable and scalable on-demand computing services at distributed environments but there is yet to be a generally acceptable design guideline to tailor the APIs and usage model of providers. As such, the standardizing of APIs for commercial software applications is perhaps an area worth considering in the construction industry.

API may be released with the option of total control by its owner or making it freely available to the public. With total control, information can be protected from the general public and owners can moderate and monitor those who use the API. Major computer game vendors used this option to obtain licensing revenue from clients. On the other hand, open API is public and allows software to be written to such platforms. Microsoft windows API and Revit API are good examples in this category. It is documented that API cannot be copyrighted in the USA as it will mean that anyone could copyright one version of code to carry out a system of commands and prevent all others from creating their own different versions to perform all or part of the same commands [13].

There are many types of API implementations. Conventional API types include DirectX and ODBC for Microsoft Windows, OpenGL cross-platform Graphic, OpenMP for shared memory processing, OpenAL cross platform-sound etc. Among the varied implementations of API, the work by Buck and Hollingsworth [14] on runtime code patching (Dyninst API) is of interest. It is a post-compile programme manipulation tool with $\mathrm{C}++$ class library for programme instrumentation. Variety of applications including debugging, performance monitoring and support for the compositions of existing packages can all benefit from using API to effect runtime code changes. This generally entails insertion of code into a running programme without the need to recompile, re-link, or restart. When the new block of code modified by the inserted code is executed by the programme, it will do so in addition to the original code thereby effecting corresponding changes into the programme. The Dyninst API can either be used to augment existing programmes or alter the semantics relating to subroutines and data structures at runtime. This will particularly be useful for researchers wishing to use existing BIM-enable platforms with similar API code patching capabilities as test-beds for prototyping purposes. Thus, API provide encapsulation mechanism for underlying information and serve as a means to modify underlying information schema and particular implementations without directly affecting third-party developers or end users of AEC systems [15].

API interfaces will invariably have limitations. The main limitation is the dependability of the plug-in on the software it is interfacing with. This includes the restrictions to particular software platform or operating system and the need to update the plug-in whenever the software is updated (due to issues of backward compatibility). Thus API implementation has the drawback that they have to be frequently updated to remain operational with new versions of software and new licenses.

\subsection{BIM extensions using API implementation}

BIM embodies much of the vision of previous academic research on data integration and management. This has been largely achieved through the reliance on data exchange standards or API level customisation for interoperability [16]. The import and export functionality of CAD and BIM tools dealing with Industry Foundation Classes (IFC) models utilize the STEP API for EXPRESS defined data to access attributes of objects created at run time [17]. Also, the implementation parts of many contemporary research efforts on BIM extension have relied on API programming technology to establish communication with models in existing BIM-enabled platforms. In this paper, BIM extensions refer to new software systems that add additional functionality to BIM-enabled tools through API-based add-on applications. The extraction of construction-specific information from BIM to improve downstream activities in construction management used API implementation to capture attributes, geometry and spatial information of element features [18]. A BIM-based system for the estimation and planning of waste from demolition and renovation works leveraged on API link offered by Revit [19]. Ruppel and Schatz [7] also relied on API technology to explore the effect of building condition on human behaviour during the 
evacuation process in the case of fire using serious gaming approach and BIM. This research effort seeks to overcome the reality with the impossibility of conducting rescue test in an actually burning building. In the US, there has been an interesting research effort to incorporate Leadership in Energy and Environmental Design (LEED) criteria into BIM tools. Nguyen et al [6] proposed an API implementation to use BIM to evaluate the sustainability of architectural designs by storing the LEED criteria indicators as project parameters in Revit Architecture software. These parameters are extracted when applied to a project to compute the maximum possible LEED ratings. Table 1 provides a list of other works developed around API and BIM applications in the construction sector. The list which is by no means exhaustive cuts across several speciality areas in construction and reveals increased interest about API implementations that used architectural BIM-enabled tools.

Table 1: BIM API application areas

\begin{tabular}{|c|c|c|c|c|}
\hline Source & BIM tool & Area of application & $\begin{array}{l}\text { Used } \\
\text { programmes }\end{array}$ & Features \\
\hline $\begin{array}{l}\text { Wang et al, } 2010 \\
{[\mathbf{2 0}]}\end{array}$ & $\begin{array}{l}\text { Revit } \\
\text { Architecture }\end{array}$ & $\begin{array}{l}\text { Sustainable building - } \\
\text { Architectural design }\end{array}$ & $\begin{array}{l}\text { Revit API } \\
\text { C\# }\end{array}$ & $\begin{array}{l}\text { - Connection of computational building modelling and } \\
\text { climatic parameters } \\
\text { - Building envelope } \\
\text { - Solar analysis }\end{array}$ \\
\hline $\begin{array}{l}\text { Yan et al, } 2011 \\
\text { [21] }\end{array}$ & $\begin{array}{l}\text { Revit } \\
\text { Architecture }\end{array}$ & $\begin{array}{l}\text { Architectural } \\
\text { visualisation }\end{array}$ & $\begin{array}{l}\text { Revit API } \\
\text { C\# } \\
\text { XNA } \\
\text { Framework }\end{array}$ & $\begin{array}{l}\text { - Integration of BIM and games } \\
\text { - Character modelling and visualization }\end{array}$ \\
\hline $\begin{array}{l}\text { Yan et al, } 2013 \\
\text { [22] }\end{array}$ & $\begin{array}{l}\text { Revit } \\
\text { Architecture }\end{array}$ & Building performance & $\begin{array}{l}\text { Revit API } \\
\text { C\# } \\
\text { Modelica }\end{array}$ & $\begin{array}{l}\text { - Multi-domain simulation of thermal and daylighting } \\
\text { - Integrating architectural design with building } \\
\text { performance }\end{array}$ \\
\hline $\begin{array}{l}\text { Zhang et al } 2013 \\
\text { [23] }\end{array}$ & $\begin{array}{l}\text { Tekla } \\
\text { Structures }\end{array}$ & $\begin{array}{l}\text { Construction and } \\
\text { planning }\end{array}$ & Tekla API & $\begin{array}{l}\text { - Detection of safety Hazards on Fall protection } \\
\text { - Rule-based safety checking }\end{array}$ \\
\hline $\begin{array}{l}\text { Irizarry et al, } 2013 \\
{[24]}\end{array}$ & $\begin{array}{l}\text { Revit } \\
\text { Architecture }\end{array}$ & $\begin{array}{l}\text { Supply chain } \\
\text { management }\end{array}$ & $\begin{array}{l}\text { Revit API } \\
\text { C\# }\end{array}$ & $\begin{array}{l}\text { - Integration of GIS and BIM } \\
\text { - Supply chain categorisation }\end{array}$ \\
\hline $\begin{array}{l}\text { Chen et al, } 2013 \\
\text { [25] }\end{array}$ & $\begin{array}{l}\text { Revit } \\
\text { Architecture }\end{array}$ & $\begin{array}{l}\text { Security in building } \\
\text { operation }\end{array}$ & Revit API & $\begin{array}{l}\text { - Integration of CCTV application into BIM } \\
\text { - Visualization of coverage of CCTV systems }\end{array}$ \\
\hline $\begin{array}{l}\text { Bank et al, } 2010 \\
\text { [26] }\end{array}$ & $\begin{array}{l}\text { Revit } \\
\text { Architecture }\end{array}$ & $\begin{array}{l}\text { Sustainable building } \\
\text { design }\end{array}$ & $\begin{array}{l}\text { Revit API } \\
\text { AnyLogic }^{\mathrm{TM}} \\
\text { (XJ Tech.) } \\
\text { C\#/VB,Java }\end{array}$ & $\begin{array}{l}\text { - New data sharing process } \\
\text { - Decision making tool for sustainable design }\end{array}$ \\
\hline $\begin{array}{l}\text { Vilkner et al, } \\
2007[27]\end{array}$ & Not stated & Structural Design & Not stated & $\begin{array}{l}\text { - Assembly of CAD documents as structural information } \\
\text { models } \\
\text { - Automation of the exchange of structural design data } \\
\text { between 2D and 3D analysis models and BIM }\end{array}$ \\
\hline $\begin{array}{l}\text { Lin and } \mathrm{Su}, 2013 \\
{[\mathbf{2 8}]}\end{array}$ & $\begin{array}{l}\text { Revit } \\
\text { Architecture } \\
\text { Revit MEP } \\
\text { Navisworks }\end{array}$ & $\begin{array}{l}\text { Mobile facility } \\
\text { management }\end{array}$ & $\begin{array}{l}\text { VB.NET } \\
\text { ADO.NET }\end{array}$ & $\begin{array}{l}\text { - Access and review 3D BIM models to update } \\
\text { maintenance records } \\
\text { - Proposes a mobile visual tool for facility management }\end{array}$ \\
\hline $\begin{array}{l}\text { Chen and Huang, } \\
2014 \text { [29] }\end{array}$ & $\begin{array}{l}\text { Revit } \\
\text { Structures }\end{array}$ & $\begin{array}{l}\text { Safety and Rescue } \\
\text { operation }\end{array}$ & $\mathrm{C}++$ & $\begin{array}{l}\text { - Combined network analysis with BIM } \\
\text { - Modelling of rescue roots in actual building conditions } \\
\text { - Propositions of low risk route finding application } \\
\text { during rescue operations }\end{array}$ \\
\hline $\begin{array}{l}\text { Kota et al, } 2014 \\
\text { [30] }\end{array}$ & $\begin{array}{l}\text { Revit } \\
\text { Architecture } \\
\text { 3DS Max }\end{array}$ & Building performance & $\begin{array}{l}\text { ADELINE } 2.0 \\
\text { C\# } \\
\text { DAYSIM }\end{array}$ & $\begin{array}{l}\text { - Integration of BIM and daylight simulations } \\
\text { - Generation renderings and annual daylighting } \\
\text { illumination } \\
\text { - Validation of geometry and material data translation. }\end{array}$ \\
\hline $\begin{array}{l}\text { Ho et al, } 2013 \\
\text { [31] }\end{array}$ & $\begin{array}{l}\text { Revit } \\
\text { Architecture }\end{array}$ & $\begin{array}{l}\text { Knowledge } \\
\text { management }\end{array}$ & $\begin{array}{l}\text { Revit API } \\
\text { VB.NET }\end{array}$ & $\begin{array}{l}\text { - BIM based knowledge sharing management for project } \\
\text { managers }\end{array}$ \\
\hline $\begin{array}{l}\text { de Laat and van } \\
\text { Berlo, } 2011 \text { [32] }\end{array}$ & $\begin{array}{l}\text { BIMsever } \\
\text { IFC }\end{array}$ & $\begin{array}{l}\text { Survey - Geospatial } \\
\text { information System }\end{array}$ & $\begin{array}{l}\text { OWS-4 } \\
\text { JAVA }\end{array}$ & $\begin{array}{l}\text { - Integration of BIM and GIS } \\
\text { - Development of CityGML extension } \\
\text { - Conversion of IFC to CityGML }\end{array}$ \\
\hline $\begin{array}{l}\text { Jaly Zada et al, } \\
2014[33]\end{array}$ & $\begin{array}{l}\text { Revit } \\
\text { Structures }\end{array}$ & $\begin{array}{l}\text { Versioning in } \\
\text { collaborative design }\end{array}$ & $\begin{array}{l}\text { Revit API } \\
\text { C\# } \\
\text { IFC }\end{array}$ & $\begin{array}{l}\text { - Tracking of revisions in collaborative design } \\
\text { - Proposed the implemented of versioning through IFC- } \\
\text { based file exchange }\end{array}$ \\
\hline $\begin{array}{l}\text { Oti and Tizani, } \\
2015 \text { [5] }\end{array}$ & $\begin{array}{l}\text { Revit } \\
\text { Structures }\end{array}$ & $\begin{array}{l}\text { Structural } \\
\text { sustainability }\end{array}$ & $\begin{array}{l}\text { Revit API } \\
\text { C\# } \\
\text { SQL }\end{array}$ & $\begin{array}{l}\text { - Proposed sustainability appraisal of alternative } \\
\text { conceptual design solutions } \\
\text { - Utilized principle of feature extraction } \\
\text { - Considered LCC, carbon and ecological footprint }\end{array}$ \\
\hline
\end{tabular}


The existence of commercially available design and modelling tools for manipulating parametric building models since the early part of the last decade has been well acknowledged [16]. These tools are essentially software systems used to create digitized building models. Some of the current providers of these systems include Autodesk, Bentley Systems, Nemetseck, Graphisoft etc. The API platform (Revit API) provided by Autodesk appears to feature more in research works on BIM applications and extension as gathered from Table 1. This is probably because it is open for developers to use and without legal restrictions for research purposes. The Revit API allows users and developers to write programmes or scripts that add new functionality to extend the capabilities of Revit platform applications [19]. The Revit Platform API is accessible by languages compatible with the Microsoft .NET Framework, such as Visual C\# or Visual Basic .NET. Developers can add functionality to an application by creating and implementing External Commands and External Applications which become accessible from the design and modelling environment of Revit platform.

\subsection{Challenges with modelling sustainability decision support in BIM}

Like many other $\mathrm{nD}$ building performance issues, integrating sustainability decision modelling into BIM is still in the infancy stage. The challenges with BIM-sustainability modelling integration can be classified into two categories. One category is the difficulty associated with obtaining a comprehensive definition of sustainability and including all the terms of such definitions in the initial phase of the modelling process. The other category relates to the difficulty associated with the techniques of mapping objects, data and rules from holistic sustainability definitions into BIM. Generally, the impacts of products from construction are considered from three angles - economic, environmental and social - based on the triple bottom line concept [34]. The time period of these impacts that fulfils sustainability considerations span from the present to the 'infinite' future as spelt out in the Brundtland Report [35]. This vast time span has imposed some complexity in the assessment of the sustainability of products [36]. Researchers have therefore suggested a life cycle approach [37] to tackling the associated challenges to avoid shifts and overlaps in the product system. These complexities are further compounded in the building artefact because of its peculiar characteristics of large size, fragmentation, long-life span and composition of a variety of contrasting materials. As such, sustainability in the built environment has been difficult to define [38]. Buildings are complex and composed of generally high order products that incorporate different technologies assembled according to unique processes [39]. Also, there are varied views on issues surrounding sustainability assessment in the sector due to the fragmentation of the industry and the diverse background/interest of different stakeholders involved in publishing information on renewable energy technologies [40]. Berardi [41] therefore suggested that building sustainability should be evaluated for every subcomponent, the integration of subcomponents in functional units and assembled systems (e.g. the air conditioning system, the envelope), as well as for the entire building.

Quite a number of countries have developed building environmental performance assessment tools tailored to their local conditions. Some of these tools also have the potential of being applied internationally as reviewed in [39, 42]. The tools have been classified into three groups: (i) product comparison; (ii) decision support and (iii) whole building framework. The more widely used tools such as - Building Research Establishment Environmental Assessment Method (BREEAM) and Leadership in Energy and Environmental Design (LEED), developed in the UK and USA respectively, belong to the third category which portrays a more comprehensive application than the former two. While acknowledging the existence of sustainability assessment and energy labelling of building products as approaches to sustainability evaluation of building, they essentially constitute database for sustainability analysis. This is because the complex nature of building makes it require a holistic and integrated evaluation system [39]. It gets even more complex with requirements extending to the need to evaluate social and economic parameters [36]. This further exacerbates to the prolonged pursuit of the realization of a universally accepted sustainability assessment system.

Notwithstanding, in recent times, the industry has witnessed the release of a number of international standards related to building sustainability. The key ones of interest are ISO 15392:2008 and BS EN 15643-1:2010 respectively detailing the general principle of sustainability in building construction and the general framework of assessment of buildings. Sustainable buildings are expected to satisfy technical and 
functional performance requirements while targeting the achievement of economic, environmental and social aspects of sustainability [43]. Sustainability assessment combines clients requirements, regulatory requirements, functional requirements, technical requirements with those of the environment, economic and social elements for the building. Integrated building performance encompasses environmental, social and economic performance as well as the technical and functional performance which are intrinsically related to each other [44]. Assessment of these three dimensions may be done separately, depending on scope and must be reported as such. It is also possible to link results from the three sustainability dimensions based on the same functional equivalence. This can form the basis for comparing building levels [44].

The building sustainability arm of European Committee for Standardization (CEN/TC 350) is working on ways to standardize aspects related to assessment procedures and communication of results from defined indicators. The construction industry will still be faced with issues regarding holistic sustainability assessment until these standardizations become complete for implementation. As awareness and progress towards standardization in the industry keeps improving, researchers have emphasized that it is more useful to include sustainability issues in the early stages of project development $[39,41,45,46]$. This has a greater tendency to influence the economic, environmental and social performance of projects. It is therefore important to target the design stage for incorporating building performance issues such as sustainability. For contemporary IT development, BIM provides the opportunity for exploiting nD issues such as sustainability to inform the design process $[4,47]$. BIM, currently in a maturing process, entails an information representation system characterized by parametric objects governed by rules of geometry, attributes and relations [48, 49]. Thus, as the awareness on BIM implementation keep increasing in the industry, more research and development efforts are being directed towards providing requisite building life cycle solutions on enhancing effectiveness and efficiency of project delivery. BIM extension through API implementation presents an opportunity for providing some of the needed solutions such as this demonstration in the area of structural sustainability appraisal.

\section{The conceptual sustainability modelling framework}

The proposed sustainability modelling framework targets blending sustainability appraisal requirements with those of systems implementation. This is to ensure that implementation of the appraisal framework is not carried out in isolation from the context of sustainable development in order not to undermine existing experiences and practices in construction industry and the society at large [50]. Figure 1 presents the conceptual sustainability modelling framework. The relationship between the components of the framework is illustrated based on IDEF0 notations. It corroborates the frameworks proposed by Svanerudh [51] and Nguyen et al. [6] respectively on improving design support systems and using BIM to evaluate the sustainability of architectural designs. 


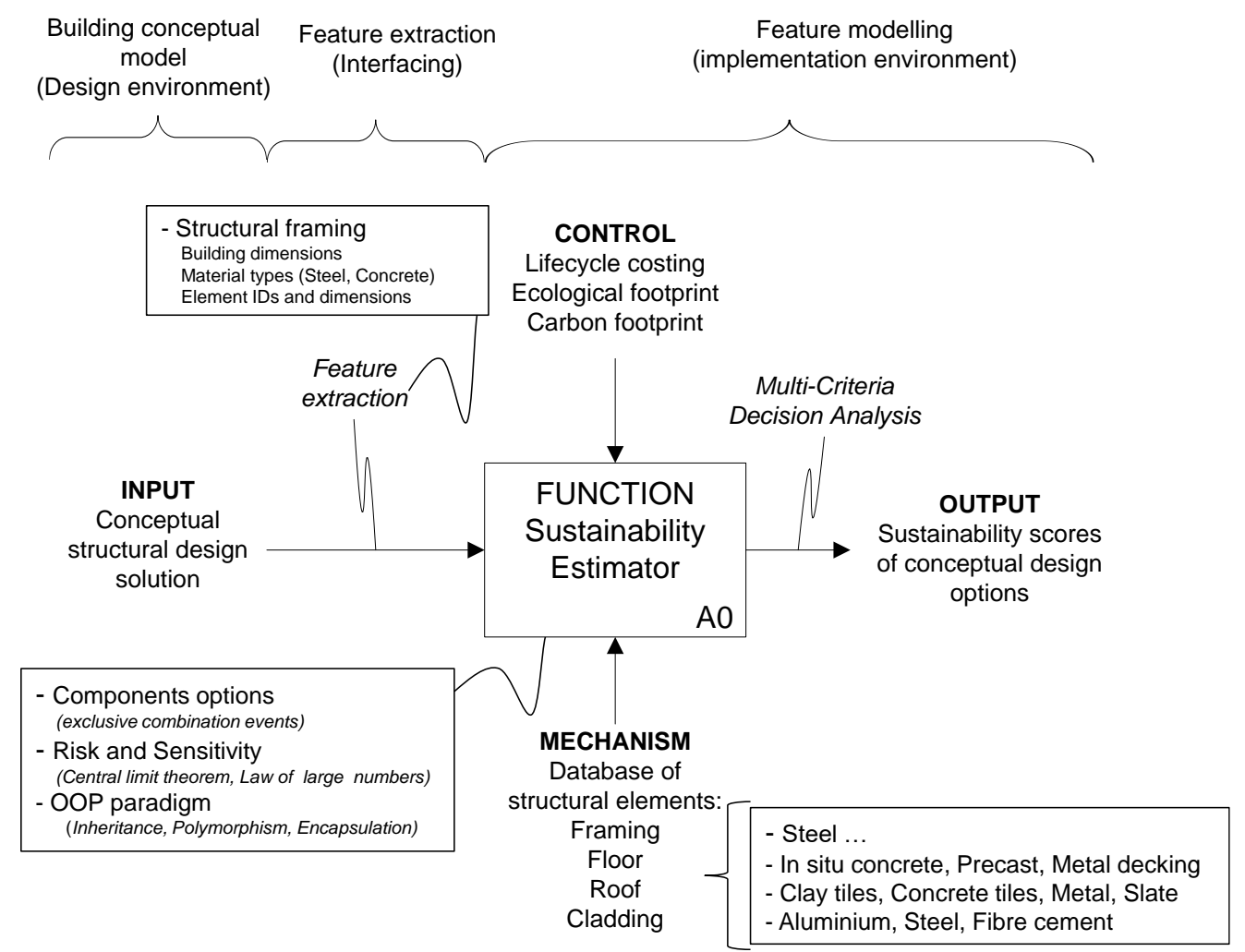

Figure 1: Components of the conceptual sustainability modelling framework

Commencing from the top of Figure 1 is the demarcation for the three major modelling components in the conceptual framework. First, there needs to be a building information model (conceptual model) in a design/modelling environment, secondly information or features need to be extracted (feature extraction) from the building model, and thirdly extracted information has to be synthesized (feature modelling) to obtain desired results. For the case of the building artefact, a feature refers to any component or element of the building which may be architectural, structural, services-related or common to the three domains. The process of recognising and identifying features from already designed artefacts and using acquired information for the purpose of building up another model (feature model) is termed feature extraction [52, 53]. Aspects of feature modelling applied in this work have been discussed in Oti and Tizani [5, 54]. Next from the top is the control. The sustainability indicators constitute the control of the system which uses features extracted from the conceptual model as input into the system. The selection and background theories of the indicators have been covered in Oti and Tizani $[5,55]$. The modelling database contains information on properties and costs of structural elements (framing, floor, roofing and cladding types) that work as mechanism based on the functional instantiations. The output of the system gives scores of design options obtained from multi-criteria decision analysis.

\subsection{Scope of the conceptual sustainability modelling framework}

The scope of implementing the sustainability modelling framework, summarised in Table 2, is limited to proof of concept to demonstrate the efficacy of the proposed system. Typical aspects of planning, construction, operation and end-of-life of materials involved in the building life cycle have been captured in the implementation which is limited to economic and environmental sustainability dimensions. The authors argue that social issues do not significantly influence structural conceptual design process as benefits of projects would have been clearly defined from the onset. Also, the methodologies to accounting for the social aspect of sustainability have not been fully developed [58]. The structural framing considered in is structural steel option include in-situ concrete and precast concrete slab construction. More specifically, the building elements covered are columns, beams, structural floor systems, and cladding and roof systems. From a structural point of view, key elements in the structural systems that are accessible for maintenance, re-use and recycling are the most important as 
they can impact on results significantly [56]. These three elements consistently feature in proposed structural engineering approach for integrated life cycle design [57] and as factors that significantly affect life cycle benefits of steel structures [58]. The implementation took the possibilities of future scope expansion into consideration.

Table 2: Scope of framework implementation

\begin{tabular}{|l|l|}
\hline Limitation areas & Description of elements considered \\
\hline Building life cycle stages & Planning and design, construction, operation and end-of-life \\
\hline Sustainability dimensions & Economic and environmental dimensions \\
\hline Structural framing options & $\begin{array}{l}\text { Structural steel including in-situ concrete and precast concrete options for } \\
\text { slab. }\end{array}$ \\
\hline Detail of building elements & Columns, beams, structural floor systems, and cladding and roof systems. \\
\hline Scope of implementation & Proof of concept \\
\hline
\end{tabular}

\subsection{The API mappings for structural sustainability appraisal}

It is the external command aspect of Revit API that has been implemented in this work. This is for the purposes of integrating the assessment of the sustainability measures of alternative design solutions to aid structural design decisions. The API implementation for assessing the structural sustainability of buildings targets the conceptual design stage where engineers are usually faced with the challenge to choose a suitable solution among alternatives. The system was implemented in the structural domain of the open Revit Platform API. It is made of two class Libraries, RevitAPI.dll and RevitAPIUI.dll. These libraries are functional when Revit is running on a system. The RevitAPI.dll is responsible for accessing Revit's application, documents, elements, and parameters at the database level while RevitAPIUI.dll takes care of all API interfaces related manipulation and customization of the Revit user interface. The associated BIM API mapping is shown in Figure 2. The feature elements such as columns, beams, floor etc. considered in the prototype are mapped into the Revit Interface as RevitElement belonging to RevitAPIObject. RevitElement has three different family categories; ComponentElements, HostElement and StructureElement to which elements belong. For example, columns and beams belong to component elements on the Revit Interface and are considered as sustainability elements on the sustainability extension (feature modelling) side. The inherent possibility of this type of object mapping presents a good advantage in enhancing the feature extraction activity. This is because the mapping of objects helps to establish the process of identification and recognition of features of interest in the conceptual model. In addition, the associated mappings serve as means for transmitting abstracted information from the feature recognition activity.

The environment for the implementation of the framework is in two parts: (1) the design environment in which the building model (combination of objects) is created and (2) the programming environment where the required objects, components, classes and their corresponding attributes are instantiated. These environments, which have been carefully chosen, evolved in course of the implementation of the sustainability modelling framework. Computer based environments for carrying out engineering designs vary and have improved in intelligence over the years. The earlier CAD systems produced plotted drawings based on vectors, line types and layer definitions [48] which has moved on to contemporary object-based modelling technology associated with objects, attributes, processes, relationships and rules. The latter, also known as parametric modelling, have been developed in a number of commercial platforms such as Autodesk Revit, Bentley Systems, ArchiCAD, Digital Project, Tekla Structures and Dprofiler. In this research, a platform - which has (1) a dedicated building modelling and design (structural engineering and architectural) section (2) supports object or feature extraction (3) accommodates interaction with external plug-in object-oriented interface - is required. The Revit platform was found to be suitable with rich SDK documentations and it is also readily available to researchers at subscribing institutions of higher learning. Although other BIM platforms have not yet been explored, the focus was on the API rather than the server application. The authors are also of the opinion that provisions 
can be made to accommodate similar API based implementations. The Revit .NET API allows programming with any .NET compliant language such as Visual Basic.NET, C\#, and C++/CLI [59].

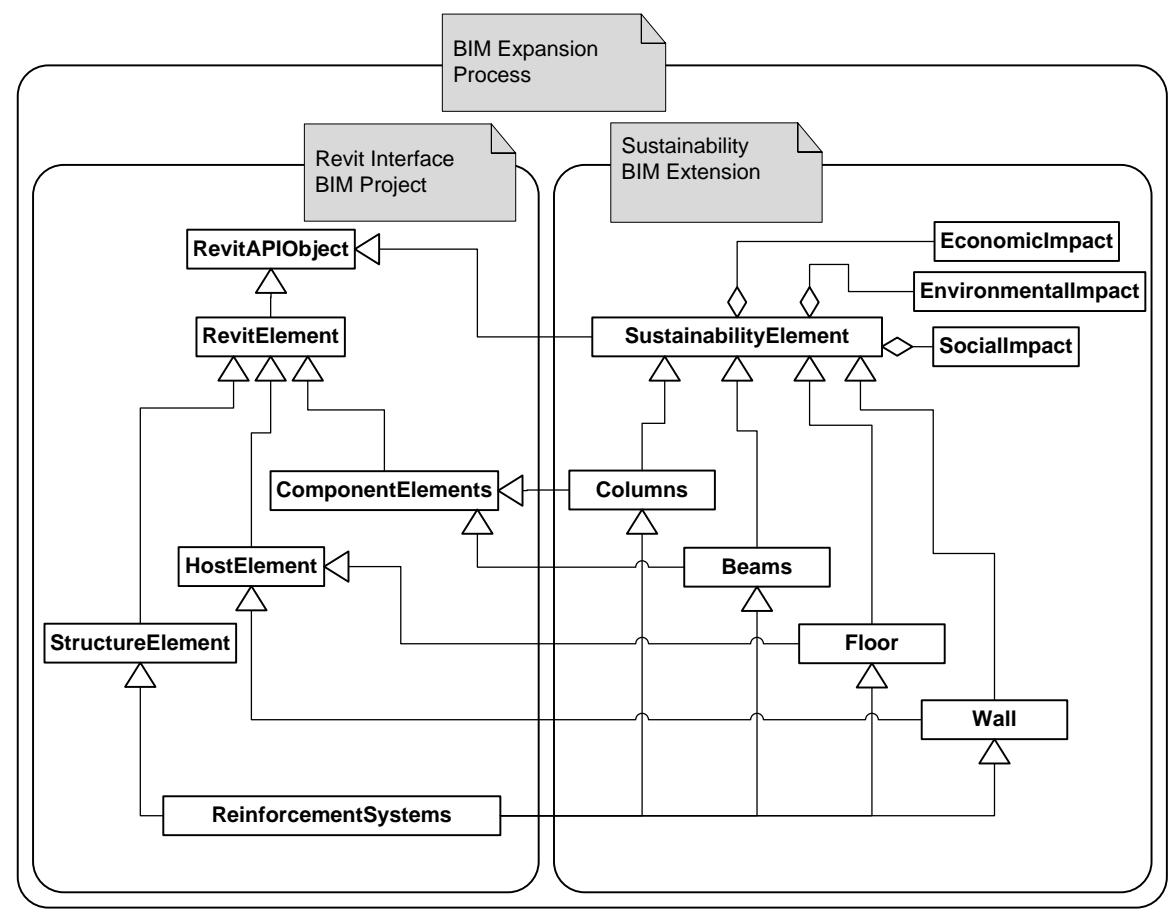

Figure 2: Possible mappings linking sustainability extension to BIM project (Revit Structures)

Among the options of programming languages in the Visual Studios .NET that can interact with the design environment, C\# came out as the most preferred. Although, the initial code development phase of the implementation was carried out independent of the design environment (in this case Revit Structures ${ }^{\mathrm{TM}}$ ), C\# had the advantage of having an in-built class library, possibility of quick development of applications and good flexibility for accessibility, communication and adaptation to other software systems [60]. In this respect, instantiations that require applications of XML, database systems (Structure Query Language) and appropriate Report Definition Language (RDL) have been made easy to deploy. It is worth mentioning that all these aspects of implementation can also be achieved using Visual Basic .NET. However, C\# was chosen due to the proficiency and preference of the researcher.

\subsection{Prototype implementation}

The prototype implementation is in two parts and employs the feature modeling approach. The first aspect involves developing a sustainability assessment model of design features using object-based modeling techniques in C\# .NET environment. This aspect was initially implemented independent of the BIM environment where conceptual design activity is performed. The second aspect entails integrating the sustainability assessment model with conceptual building design iterations in the building information modeling process. This second aspect is developed based on the processes associated with feature extraction activity. The fundamental activities making up these two aspects of the prototype implementation include use-case elicitation, development of programming algorithms and the process of representing features as objects in the programming environment.

The elicitation of a use-case and its component interactions used to guide the programming directions are presented in Figure 3 and Table 3 respectively. The sources of information for developing the use-case are through domain knowledge analysis [50,61], related literatures [62,63] on the subject and refinement through regression testing of the framework. The use-case portrays how the actor, a structural engineer in this case, interacts with the proposed system to produce appraisal results of alternative design solutions. It entails the structural engineer registering his project information and design details, and feeding in required information related to cost components, impact of elements and time. The economic and environmental appraisal could then be carried out through appropriate indexing and 
weighting strategy from generated results on the corresponding indicators. At this stage, the onus rests on the engineer on how to combine the indicators to make a judgement vis-à-vis other factors such as prestige, future potential changes and project longevity. Sequence of actions characterizing components of the use-case diagram is further captured by algorithms guiding the implementation of the sustainability appraisal framework.

The first column (Use-case scenario) of Table 3 captures the intention of the Actor to carry out a sustainability appraisal and associated responsibilities in the use-case scenario of Figure 3 . The corresponding action of the actor to extend this intention as messages to the system are given in the second column (Instances of the Actor's action) action messages sent to the system. The direct responses of the system to these actions and the internal processes triggered in the system to fully execute corresponding functions of the system are detailed in the third column (Functions of the System and responses). The sustainability decision support algorithm (Figure 4) was developed based on the use-case scenario and therefore reflects the use-case interactions detailed in Table 2. For example use-case scenarios 1 (Enter Project Information ) and 2 (Enter details of design result) in the table are combined in the Project Registration box of the figure capturing the instances of the actor's action such as registering the project information by providing project title and location, design material types and building dimensions and selecting the mode of operation. The system responds in this case by storing these categories of information and initializing extracted building features for further actions.

Examining the flow chart in Figure 4 shows 7 marked key actions which include (1) the project registration aspect mentioned earlier, (2) initial cost estimation part, (3) the economic aspect represented by lifecycle cost estimation and ( $4 \mathrm{a} \& \mathrm{~b})$ the environmental aspect comprised of carbon footprint and ecological footprint measures. The remaining three sections relate to exploring what-if scenarios application for (5) combination options and (6) conducting risk and sensitivity analysis and lastly, (7) comparing design option on multiple criteria basis. The prototype operation screenshot outputs corresponding to these 7 blocks are given in Section 4.

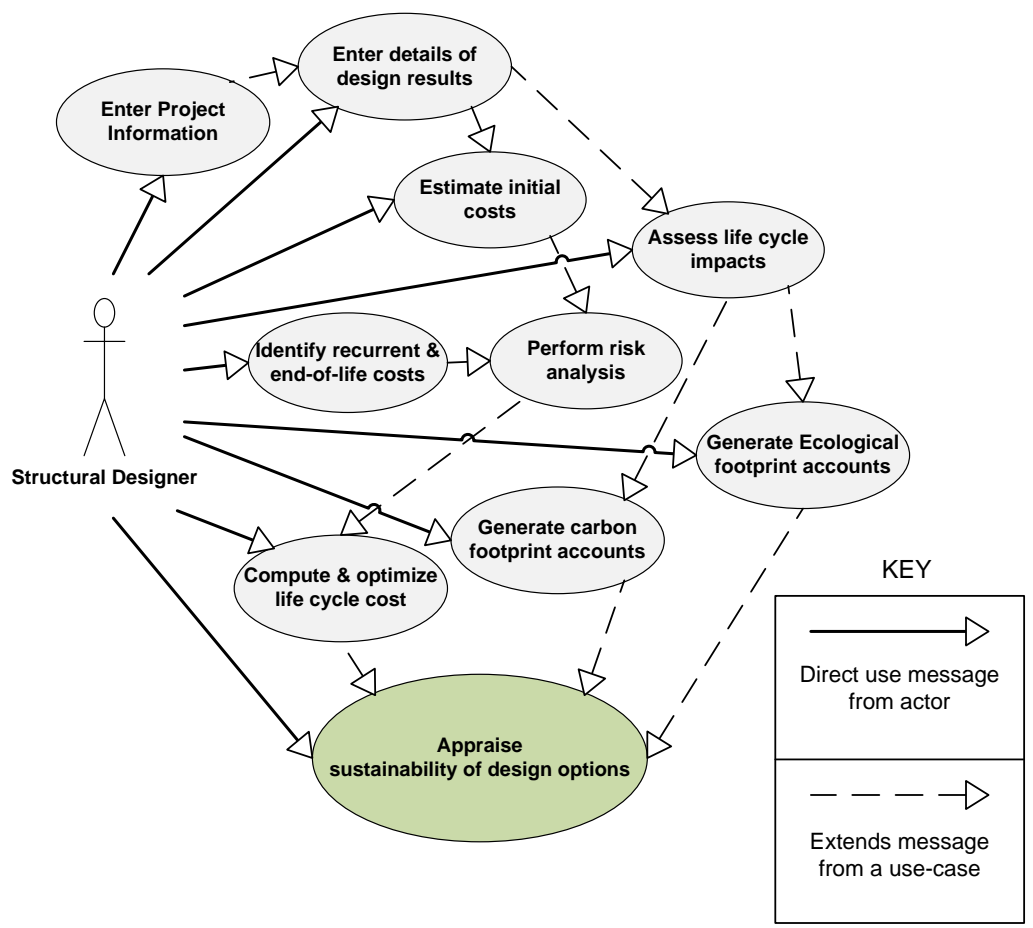

Figure 3: Use-case of structural sustainability estimation 
A.H. Oti, W. Tizani, F.H. Abanda, A. Jaly-Zada, J.H.M. Tah. 2016. Structural sustainability appraisal in BIM, Automation in Construction, 69, September 2016, Pages 44-58 http://dx.doi.org/10.1016/j.autcon.2016.05.019

Table 3: Interaction of structural sustainability use-case

\begin{tabular}{|c|c|c|}
\hline Use-case & Actor's action & System responses \\
\hline Enter Project Information & Provide project title and location & Store information \\
\hline $\begin{array}{l}\text { Enter details of design } \\
\text { result }\end{array}$ & $\begin{array}{l}\text { Specify design life, Material type and } \\
\text { building dimensions }\end{array}$ & $\begin{array}{l}\text { Initialize extracted building features, } \\
\text { store supplied information }\end{array}$ \\
\hline Estimate Initial Cost & $\begin{array}{l}\text { Inspect components and material } \\
\text { information, Instruct system }\end{array}$ & $\begin{array}{l}\text { Call stored information, Calculate } \\
\text { quantities and initial cost }\end{array}$ \\
\hline $\begin{array}{l}\text { Identify recurrent \& end- } \\
\text { of-life costs }\end{array}$ & $\begin{array}{l}\text { Provide recurrent cost, supply } \\
\text { frequencies and discount rates }\end{array}$ & Store information for initialisation \\
\hline $\begin{array}{l}\text { Compute \& optimize life } \\
\text { cycle costs }\end{array}$ & Instruct system & $\begin{array}{l}\text { Computes lifecycle cost from initial cost } \\
\text { and other determined costs }\end{array}$ \\
\hline Perform Risk Analysis & $\begin{array}{l}\text { Enter components, supply possible } \\
\text { cost variations }\end{array}$ & Simulate cases and display results \\
\hline Assess life cycle impacts & $\begin{array}{l}\text { Specify aspects of environments } \\
\text { impact to assess and proceed }\end{array}$ & $\begin{array}{l}\text { Instantiate life cycle information of } \\
\text { materials from stored data (database) }\end{array}$ \\
\hline Generate Carbon Footprint & $\begin{array}{l}\text { Specify life cycle boundary, material } \\
\text { recovery status }\end{array}$ & $\begin{array}{l}\text { Generate calculations for carbon } \\
\text { footprint measure }\end{array}$ \\
\hline $\begin{array}{l}\text { Generate Ecological } \\
\text { Footprint }\end{array}$ & $\begin{array}{l}\text { Indicate building area, Ecological } \\
\text { footprint factors }\end{array}$ & $\begin{array}{l}\text { Calculate structure's ecological } \\
\text { footprint measure }\end{array}$ \\
\hline $\begin{array}{l}\text { Appraise sustainability of } \\
\text { design options }\end{array}$ & $\begin{array}{l}\text { Provide indicators combination } \\
\text { weighting, Instruct system, inspect } \\
\text { result, make decision }\end{array}$ & $\begin{array}{l}\text { Compare options sustainability } \\
\text { measures, generate visual chart of } \\
\text { option performances. }\end{array}$ \\
\hline
\end{tabular}

The overall flow in Figure 4 entails calling up the decision-support programme from a BIM-enabled programme while carrying out structural modelling activities. The next requirement in the sequence of events is to provide requisite identification for the project by registering project information and assigning design option IDs (Identifications). The sequence of events then flows through a decision making process on three alternatives (Manual entry of building elements, Assess building from IFC model or Assess building from native BIM format) to extract building features for onward sustainability assessment. Once this decision is made and the relevant features are extracted, the sequence of assessment steps through the estimation of Initial Cost, Life Cycle Cost (LCC), Carbon Footprint, and Ecological Footprint. The theories surrounding these indicators and their selection for this study have been discussed in [5]. At decision points such as "Perform risk and sensitivity analysis" common to Initial Cost and Economic (LCC) flow blocks, the onus rests on the designers to make the decision to call the function to carry out corresponding risk and sensitivity analysis, which then moves on to the aspect of environmental analysis. The designer could explore the performance of various combinations of materials in what-if scenario situations. After saving the estimated measures of the indicators, the process can be repeated for more design options and eventually compared on multi-criteria basis of the three sustainability indicators. The comparison then brings out the most favourable design based on the relative performance of the design options. The last event in the sequence before termination is to produce necessary reports for the assessment.

In the Initial Cost Estimation part, extracted features and their corresponding properties and quantities are grouped according to component categories such as frame (beams and columns), floor, roof and cladding. This will allow easy interaction with the database management system to draw up corresponding cost information. It is important that information prone to change remain in a database separate from actual programming environment because of the need to update records periodically. After the cost of all individual elements has been calculated, the sequence moves on to sum the costs according to component categories and for the overall initial cost. At this stage it is possible to perform an early check of risks of the estimation and also identify the most sensitive cost component or component element category. More detailed risk and sensitivity check can be done when the life cycle cost measure has been 
estimated. The LCC aspect commences with the initialization of the initial cost of component element categories (Frame, Floor, Roof and Cladding). It flows through getting information such as design life and discount rates needed for the conversion of costs to present day money value. The algorithm then steps through the estimation of various cost components such as maintenance, decommissioning and residual value to aggregate the life cycle cost of components categories. This is used to obtain the overall life cycle cost.

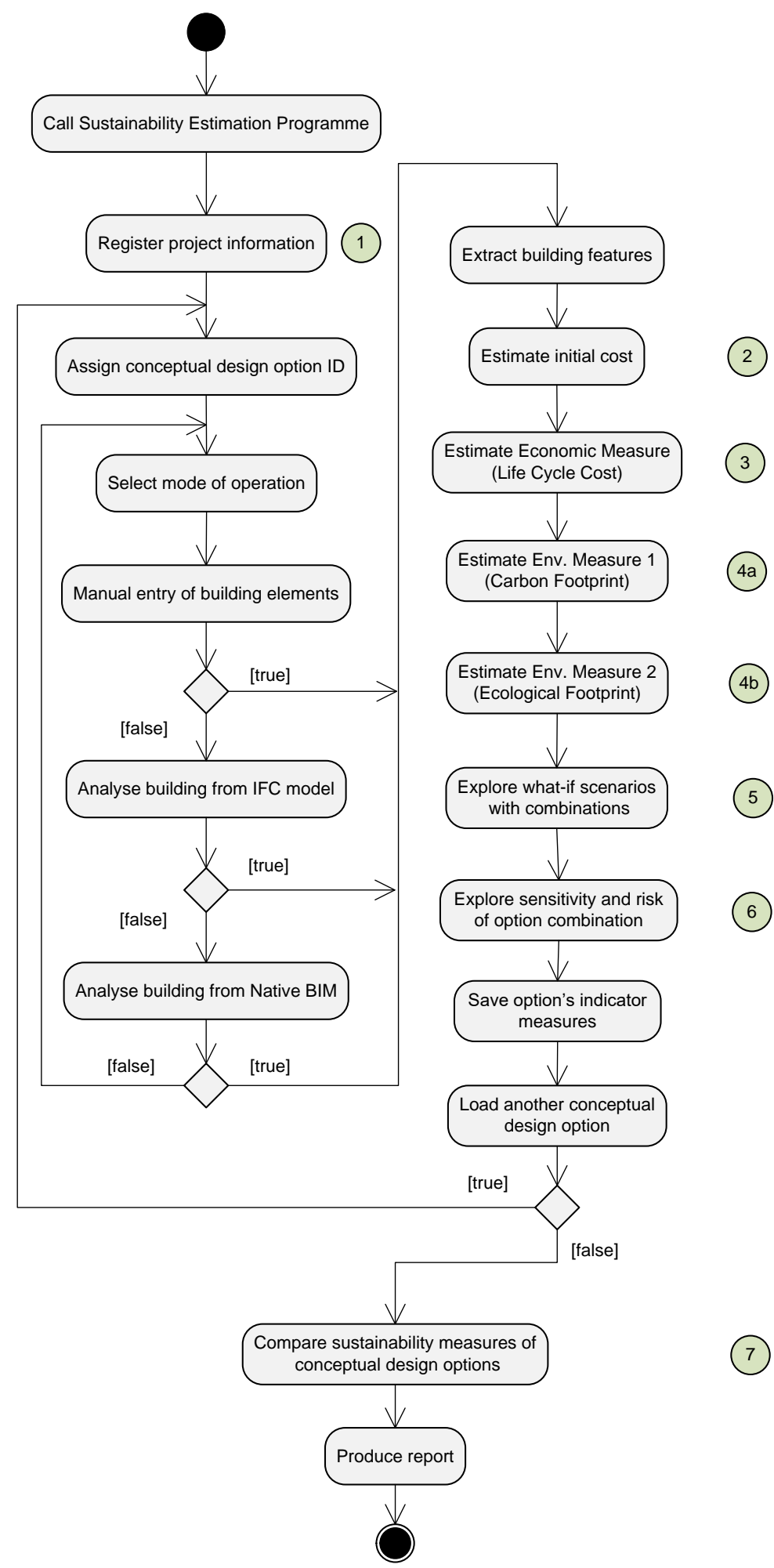

Figure 4: Sustainability estimation flow chart 
For the environmental assessment aspect, the designer is required to supply options for end-of-life boundary conditions. The underlying processes rely on the accompanying database management system to supply information on emission factors, ecology factors and embodied energy of materials. These are combined with abstracted quantities to calculate the carbon footprint and ecological footprint measures of the design options. Further details on operation of the prototype has been captured in [5].

Options are compared based on the principle of multiple criteria decision method. It essentially combines criteria with different units by apportioning performance weightings to calculate relative score of options. Weightings are provided at two levels. The first level is the economic and environmental contributions. How the carbon and ecological footprint are to be combined for the environmental aspect is specified at the second level. The system computes relative scores for the various design options being compared based on the specified weightings and identifies best performance option by the magnitude of their scores. It employs the Multiple Attribute Decision Making (MADM) which is a more suitable option of multi-criteria decision analysis. This is because the number of conceptual design options to be compared will be finite [64]. The method also has the advantage of allowing the comparison of attributes with different units of measurement by the use of weighting factors. Prototype Illustration

\section{A test-case of using the prototype}

To discuss the outputs from the prototype operation, a hypothetical 3-storey office building framed in structural steel is analysed here. The overall height of the structure is $12 \mathrm{~m}$ and $3.5 \mathrm{~m}$ between floors. The building has a plan area of $30 \times 18 \mathrm{~m}$. Figure 5 shows two conceptual structural design options for the comparison based on their respective sustainability measures. The illustration assumes that the options are alternatives developed from architectural specifications and therefore have similar input data on items such as: design life of structure; the building footprint or floor area; building surface area for cladding purposes, maintenance frequency for the various key elements; and discount rate for calculating corresponding net present values. However, the options vary in framing pattern (positioning of grids), floor type, type of cladding and materials used for roofing (Table 4). The building footprint areas are equal and remain within the confines of the architect's specification. This illustration does not separately consider openings in the floors such as for staircases as they will be similar for all options and therefore do not have any significant effect on the final output. Also, it is worth mentioning that cost related inputs are intended to demonstrate the efficacy of the prototype and not a reflection of current market values.

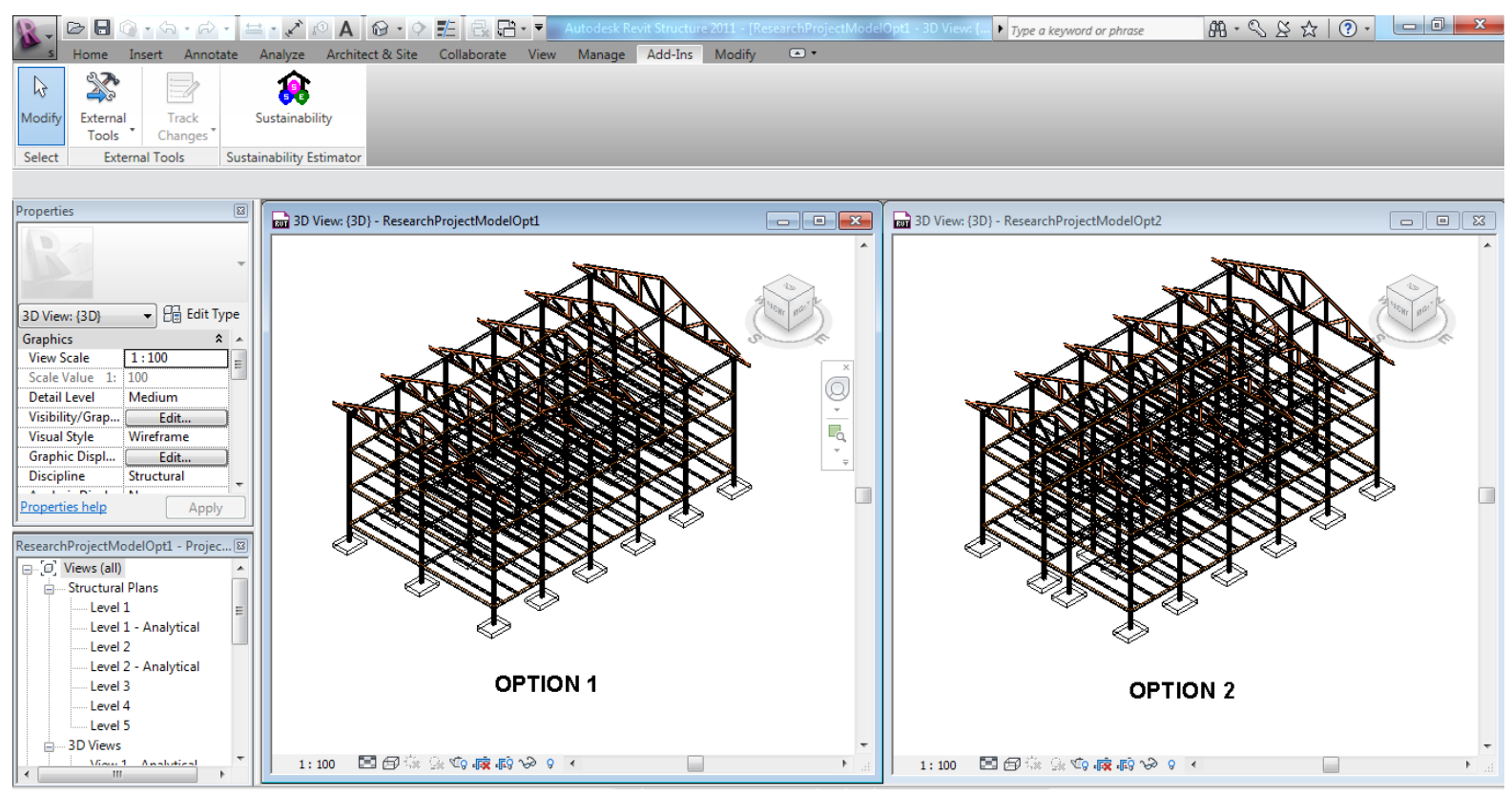

Figure 5: 3D Models of two alternative design solutions 
In the development of the prototype, only the superstructure of a building is considered for sustainability analysis since maintenance issues are not often associated with the substructure after construction is completed. Life cycle costing, carbon footprint and ecological footprint are criteria used for evaluation. The components of the life cycle cost include the initial cost, maintenance, decommissioning cost and residual value. These are the key representative components relevant for the estimation of the LCC of structural components in this work. Although a number of cost database exists, relevant materials price details have been obtained from the SPON's cost estimates [65]. Carbon footprint is currently calculated based on the embodied energy of the materials which have been sourced from Version 2.0 of the Inventory of Carbon \& Energy (ICE) [66]. Ecological footprint combines the measure of the built up land and the energy land of the structural design option. In accordance with the 6 blocks of Project Registration, Initial Cost, Economic (LCC), Environment $\left(\mathrm{CO}_{2} \& \mathrm{EF}\right)$, What-if- scenario 1 \&2 and Options Comparison in the sustainability decision support flow chart (Figure 4), corresponding main screenshots from the prototype are given in figures 7-12 .

For this illustration, the screen output in Figure 11 gives the sample output (Sustainability Index tab page) from the comparison of the two conceptual design options. The Sustainability Index tab page is preceded by six other tab pages: Material Selection, Initial Cost, Material Records, Cost Summary (Figure 8), Sustainability Parameters and Indicator Estimation (Figure 9) designed for accepting and viewing inputs from the user as well as data abstracted from the building information model. The last tab page is Reporting Services where information generated from the sustainability model could be exported to a PDF file, Excel file or a Word file for record keeping or further analysis. Typically on the Sustainability Index tab page, the designer loads the various alternative design solutions and provides the respective weightings for the economic and environment dimensions of sustainability. Also, the weightings for combining the environmental performance indicators (carbon footprint and ecological footprint) need to be specified. The default weightings for both cases have been set to 50\%:50\%. Once this is completed the sustainability score of the various options can be generated in a chart. As seen from Table 4, the sustainability (desirability) scores for the options 1 and 2 are 0.52 and 0.48 , respectively. This is obtained from applying the default weightings to the normalised values of the respective indicator measures based on principles of multi-criteria decision analysis (MCDA).

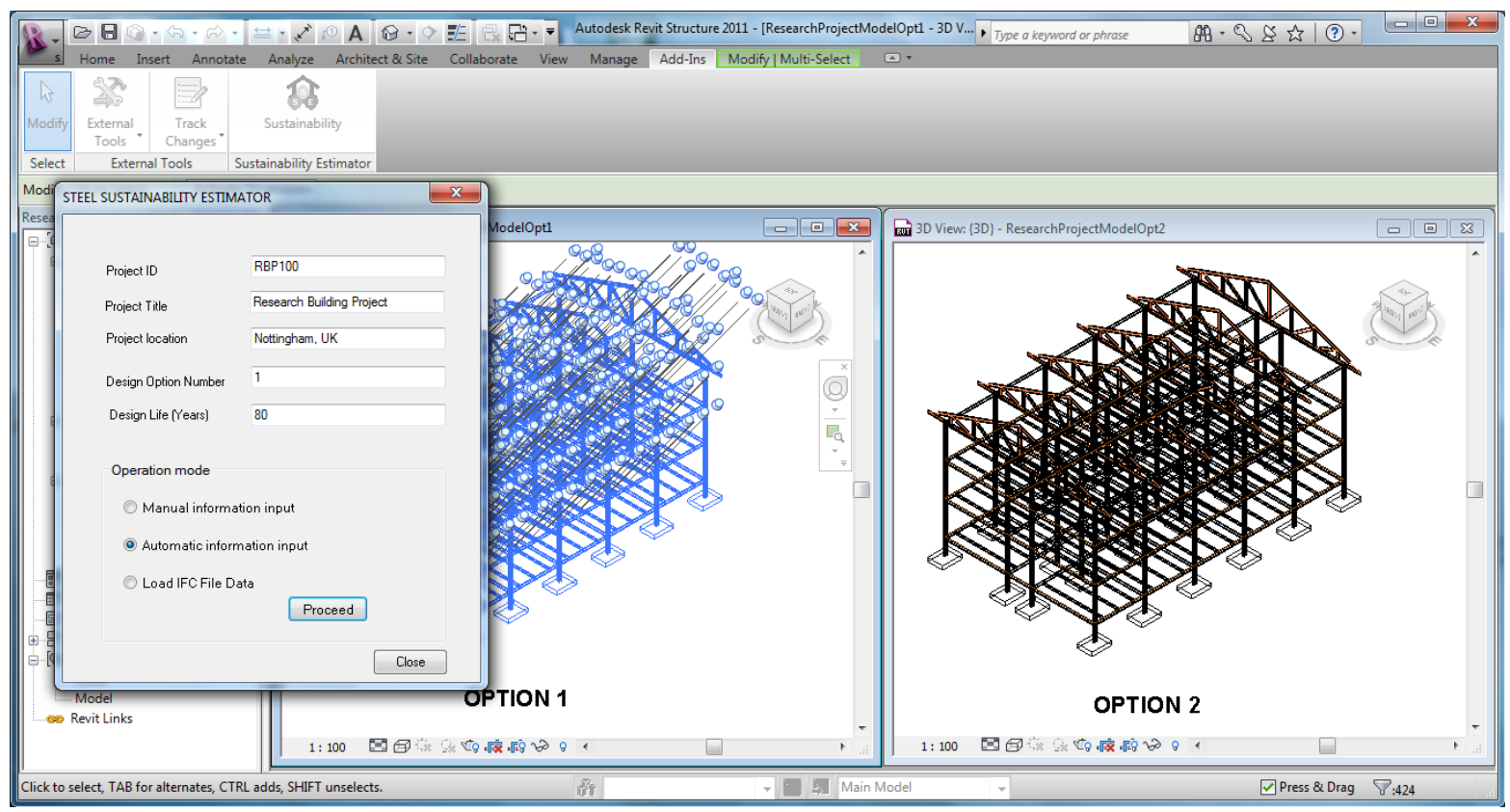

Figure 6: Project registration preliminaries 
A.H. Oti, W. Tizani, F.H. Abanda, A. Jaly-Zada, J.H.M. Tah. 2016. Structural sustainability appraisal in BIM, Automation in Construction, 69, September 2016, Pages 44-58 http://dx.doi.org/10.1016/j.autcon.2016.05.019

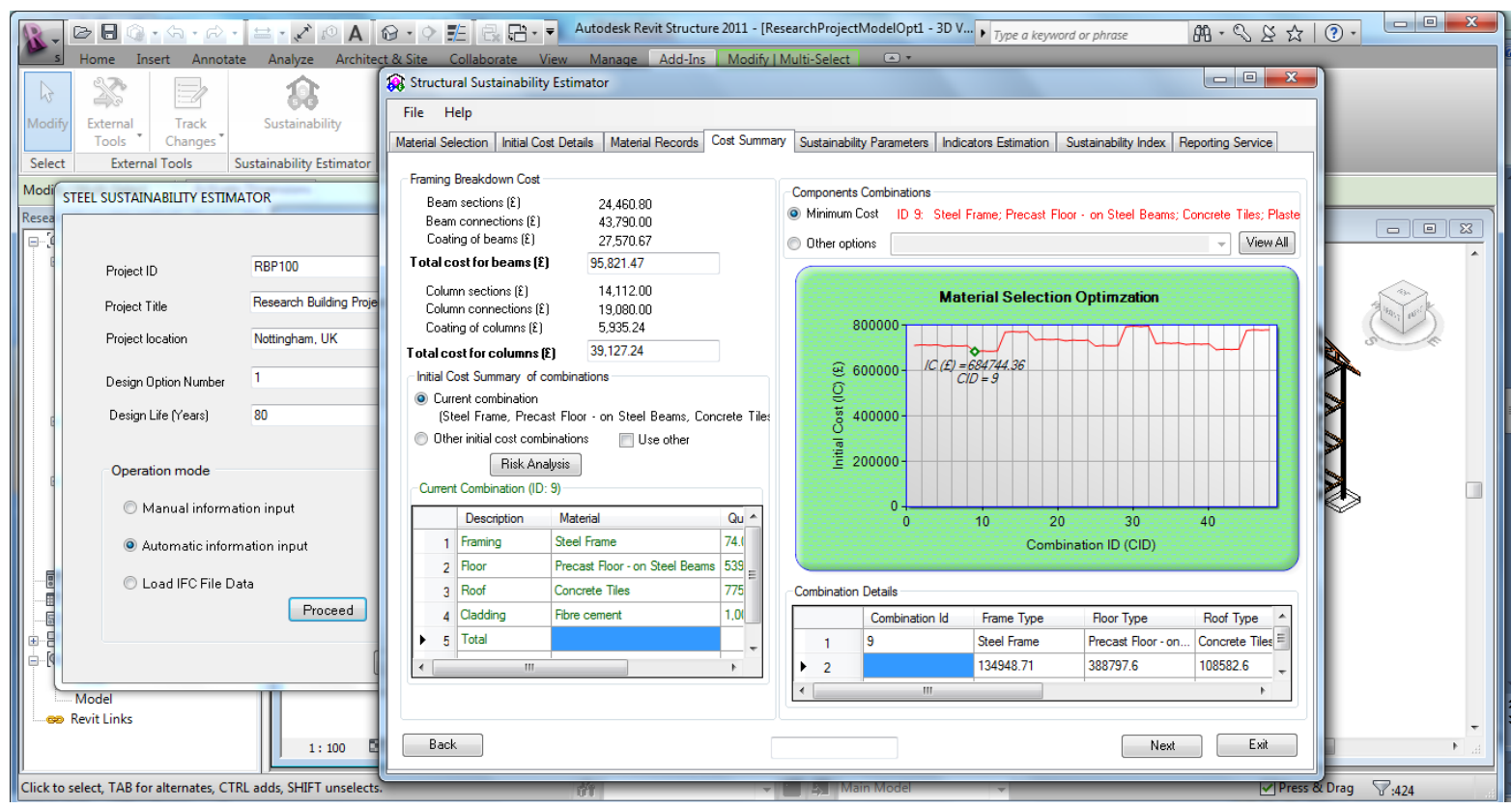

Figure 7: Initial cost summary of building's structural framing

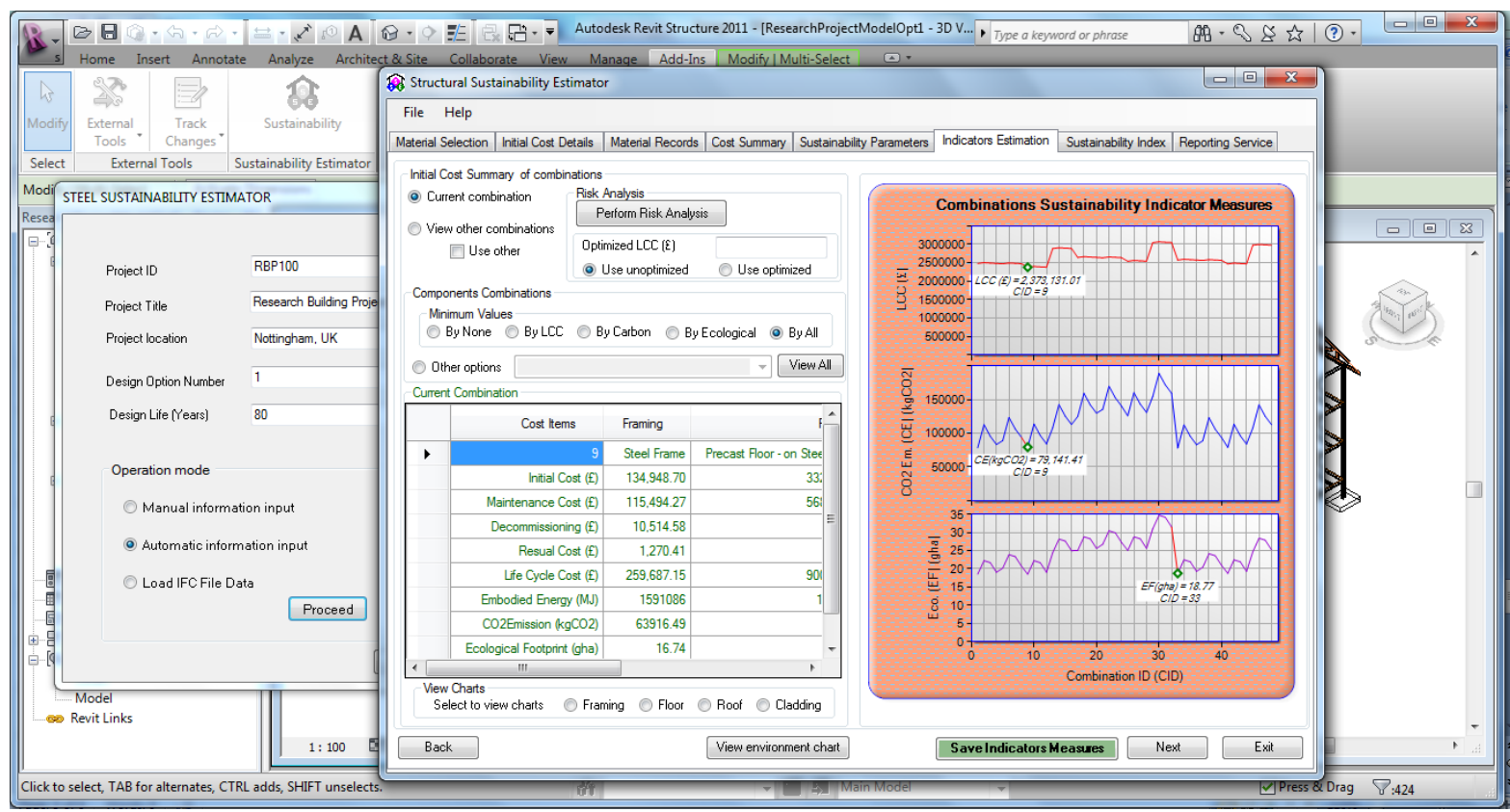

Figure 8: Output for economic and environmental analysis 
A.H. Oti, W. Tizani, F.H. Abanda, A. Jaly-Zada, J.H.M. Tah. 2016. Structural sustainability appraisal in BIM, Automation in Construction, 69, September 2016, Pages 44-58 http://dx.doi.org/10.1016/j.autcon.2016.05.019

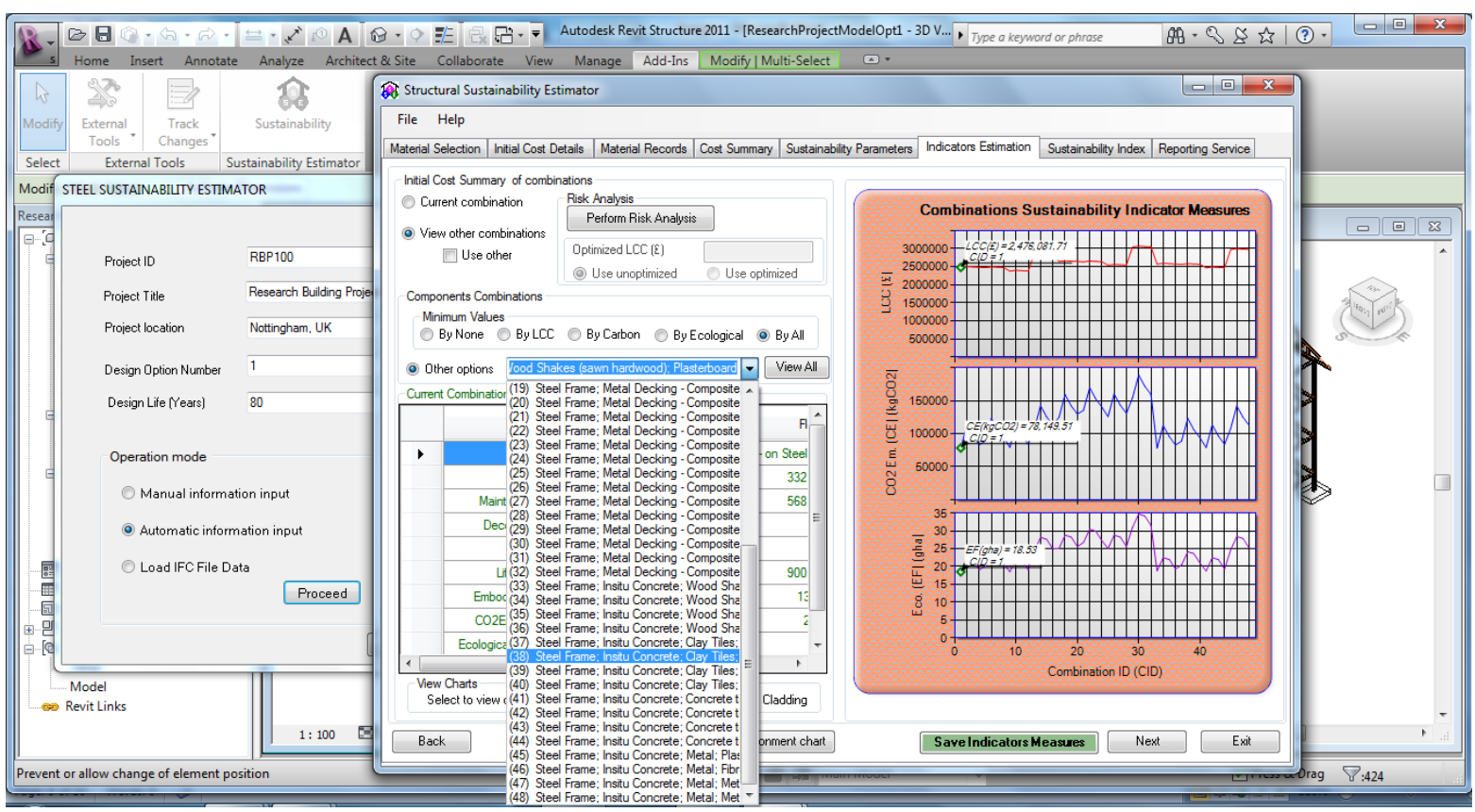

Figure 9: Exploring what-if scenario with element combination options in comboBox

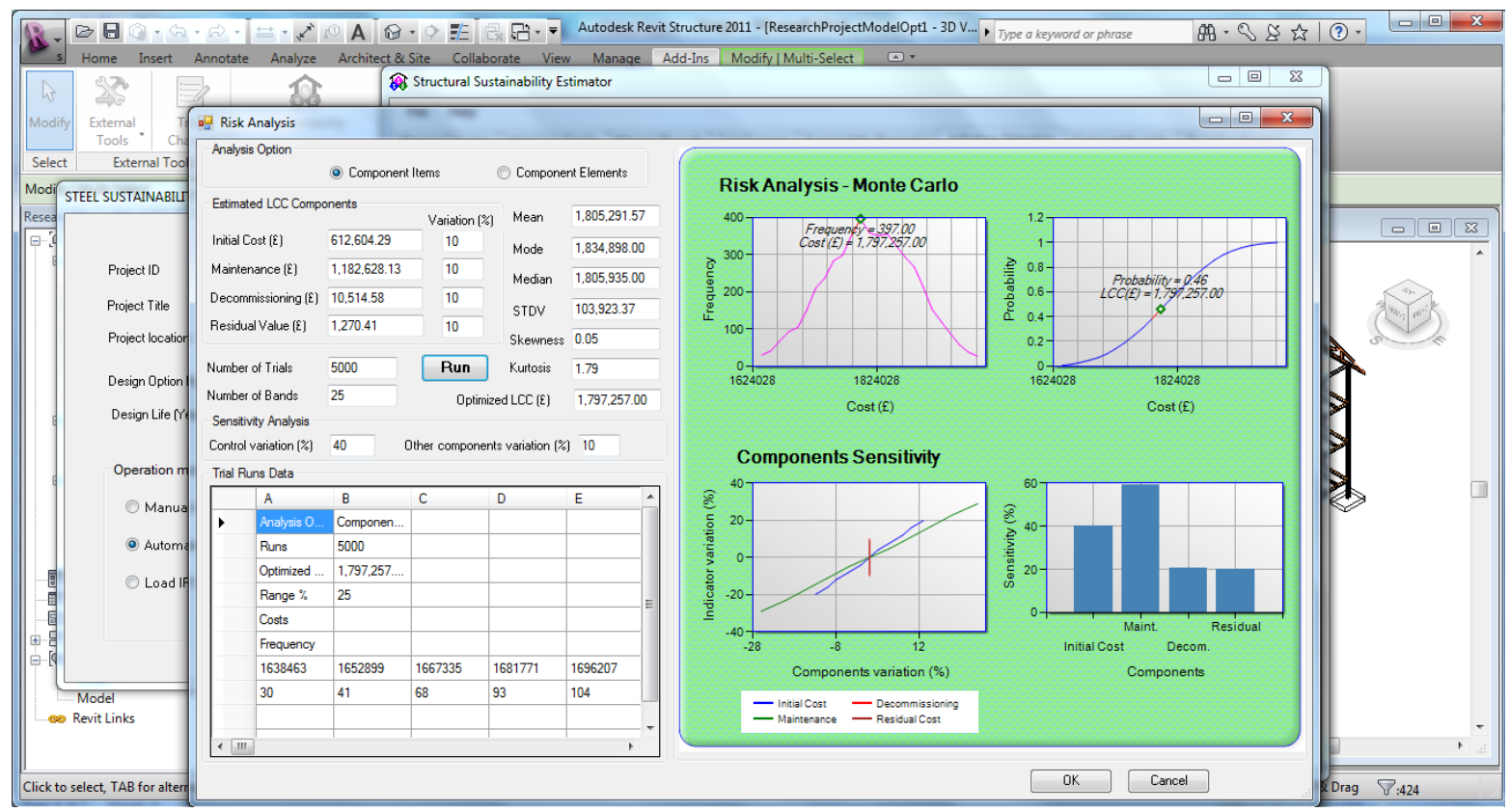

Figure 10: Life cycle cost components option of exploring risk and sensitivity 


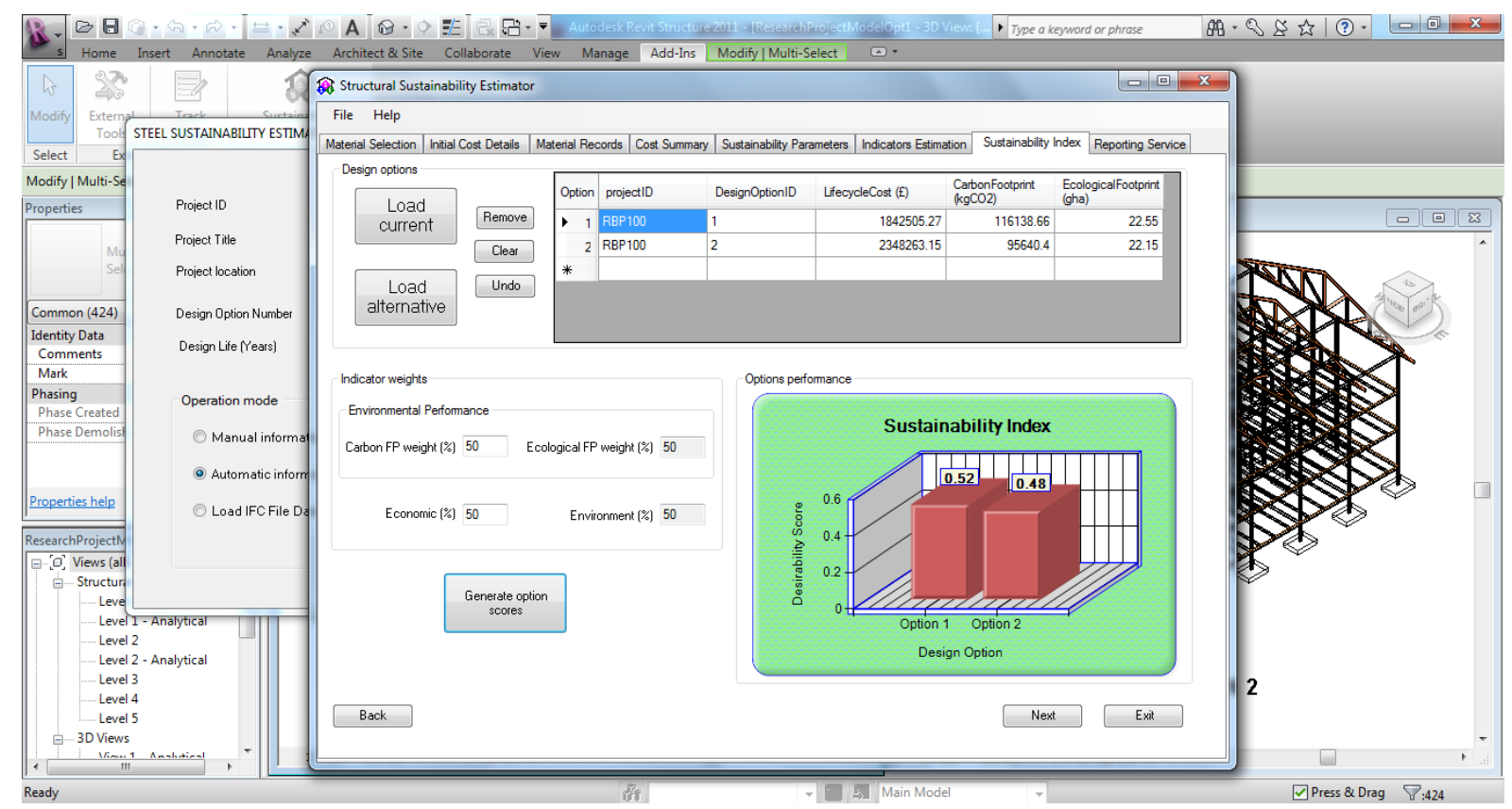

Figure 11: Output of sustainability analysis of design options

Thus, Option 1 ranks better than Option 2. That is, Option 1 has a higher sustainability score of 0.52 and it is therefore the preferred option in terms of sustainability of structural steel framing system. In the aspect of environmental sustainability, Option 2 is more favoured as it has the least measures of embodied energy, carbon footprint and ecological footprint while Option 1 is better in terms of the economic indicator of life cycle cost. Option 1 becomes the more sustainable option when the economic and environment criteria are considered on equal weighting. This condition may be altered with changes in the ration of weighting combination. The decision about how to combine weightings rests on the designer which to a large extent is subjective and requires some form of standardization by the industry. The lack of standard institutional guide for combining indicators in decision making is potentially a source of contention among professional. It is worth mentioning that there are applications relying on multiobjective evaluation techniques (e.g. Genetic Algorithm) which are not based on weighting factors. As such these applications may possess varying degrees of advantages on the optimization of combination criteria and modelling capability. An example is the BIM-based performance optimization (BPOpt) application which relies on Optimo, an open source genetic algorithm-based optimization tool developed to interact with BIM platforms such as Autodesk Revit. In this application, users are provided with a manageable iterative process to re-define decision variables using fitness functions in accordance to appropriate domain design approaches [67].

The prototype in this research was developed on the default basis of equal weightings of the indicators and sub-indicator categories in accordance to MCDA method. Although most composite indicators rely on equal weightings [68], there is some empirical basis for doing so in this research. The environment, carbon footprint and ecological footprint sub-indicators are complementary and measure two distinct important aspects of the environment: atmosphere and biosphere, respectively. These aspects are considered equally important in terms of impact. A connection of carbon exists in the two indicators [69] but this does not affect the prototype results as the same condition is applied for all the considered design options. At the main indicator level, economy and environment also constitute two out of the three key (equally important) pillars of sustainable development. This is also reflected in the Building for Environmental and Economic Sustainability (BEES) approach in combining environment and economy to select cost-effect green products [70]. 


\begin{tabular}{|c|c|c|}
\hline Description & Option 1 & Option 2 \\
\hline \multicolumn{3}{|l|}{ Input information } \\
\hline \multicolumn{3}{|l|}{ Option similarities } \\
\hline Design life (Yrs) & 80 & 80 \\
\hline Building floor area $\left(\mathrm{m}^{2}\right)$ & 540 & 540 \\
\hline Building surface area $\left(\mathrm{m}^{2}\right)$ & 1344 & 1344 \\
\hline Cladding area $\left(\mathrm{m}^{2}\right)$ & 1008 & 1008 \\
\hline Maintenance frequency (Yrs) & 10 & 10 \\
\hline Discount rate $(\%)$ & 2 & 2 \\
\hline \multicolumn{3}{|l|}{ Options differences } \\
\hline Framing weight $(\mathrm{t})$ & 82.47 & 74.00 \\
\hline Floor Type & In situ - concrete & $\begin{array}{l}\text { Precast concrete on steel } \\
\text { beams }\end{array}$ \\
\hline Cladding Type & Fibre cement & Metal-Aluminium \\
\hline Roof Material & Clay tiles & Concrete tiles \\
\hline Grid spacing & $\begin{array}{l}\text { Grid spacing @ 9m } \\
\text { centres ( } 2 \text { bays) }\end{array}$ & $\begin{array}{l}\text { Grid @ } 7.5 \mathrm{~m}, 3 \mathrm{~m}, 7.5 \mathrm{~m} \\
\text { (3 bays) }\end{array}$ \\
\hline \multicolumn{3}{|l|}{ Output information } \\
\hline \multicolumn{3}{|l|}{ Economic } \\
\hline Initial Cost (f) & 679,328 & 621,199 \\
\hline Maintenance cost (£) & $1,307,276$ & $1,212,062$ \\
\hline Decommissioning cost $(\mathfrak{f})$ & 10,671 & 10,514 \\
\hline Residual value (f) & 1,418 & 1,270 \\
\hline Life cycle cost $(\mathfrak{f})$ & $1,995,859$ & $1,842,505$ \\
\hline \multicolumn{3}{|l|}{ Environmental } \\
\hline Embodied energy (GJ) & 2,130 & 2,192 \\
\hline Carbon footprint $\left(\mathrm{kgCO}_{2}\right)$ & 95,640 & 116,138 \\
\hline Ecological Footprint (gha) & 22.15 & 22.5 \\
\hline Sustainability Score & 0.52 & 0.48 \\
\hline
\end{tabular}

\section{Relevance of prototype}

It is worth mentioning that it is practically difficult to apply existing sustainability assessment systems to directly assess the design options considered in this illustration for the purpose of comparison. This is because of differences on the basis of operation and the overall content of assessment. However, some correlation can be established between the prototype and assessment systems such as BREEAM. The BREEAM scheme covers 10 categories of sustainability [71] including management, Health and wellbeing, Energy, Transport, Water, Material Waste, Land Use and Ecology, Pollution and Innovation (Table 5). Three out of these 10 categories are directly related to the sustainability assessment proposed in this research. They include Energy $\left(\mathrm{CO}_{2}\right.$ emissions), Materials (Embodied life cycle impact, Materials reuse) and Land Use and Ecology (Protection of ecological features, Mitigation/enhancement of ecological features). Weightings in the form of credits have been assigned to the various issues considered in the BREEAM categories. On considering the main issues listed in the three categories of interest, it can be deduced that the sustainability indicators considered in the prototype can contribute about $26.02 \%$ of BREEAM overall ratings. That is to say, a design option with the best sustainability ranking assessed by the prototype is likely to score a high proportion of $26.02 \%$ of BREEAM rating. If such design option 
eventually performs well in the remaining $73.98 \%$ of BREEAM ratings, it is most likely that the BREEAM overall score will not fall below the "Good" classification.

Thus, the sustainability scores from the prototype can be used by practitioners to appraise alternative conceptual design solutions of projects. The system provides the designer additional sustainability criteria, in the form of relative desirability scores, to constructability and structural integrity for favouring a particular design solution above alternatives. Since the scores are relative to the number of alternative solutions and unique for different projects, the comparison of such different projects by the system is not tenable. Further research will be useful to develop a universal system where designs for different projects, irrespective of their differences, can be compared on a common sustainability scale. Results from such scales can then be generally applied as structural sustainability design tags of projects subject to acceptability by the industry. Scores in the prototype are dependent on weighting factors. The choice of weighting factors for indicator measures is crucial in any assessment activity. To a great extent, it determines final assessment results and is a key source for subjectivity [72]. The basis for deriving the weightings and the effects of the weighting process on the interpretation of outputs are two critical issues. Weightings of an indicator may be determined based on whether effects from sustainability impacts are reversible, long lasting and widely-spread in terms of population or area. More importantly, weightings of an assessment category could be based on the reflection of potential impact of the environmental components in question. For example, weightings should not be based on whether air pollution is more important than land pollution but instead on which of these aspect exerts a greater specific potential impact on the environment as a point of concern. As the relationships between buildings/building components and their associated sustainability impacts keep advancing through research and requisite data collection, it will become possible to establish reliable guides to assist users to apply weighting protocols to assessment criteria and to meaningfully interpret aggregated results [73].

The challenge of using varying and numerous indicators in sustainability assessment has been highlighted in literature $[39,42]$. The associated difficulties include making the assessment process cumbersome and a common basis for comparing results from various existing assessment tools elude the industry. This research featured a simplification of indicators into three measures: LCC, Carbon Footprint and Ecological Footprint as relevant to the structural domain in building construction. These indicators represent the economic and environmental aspect of sustainability deemed to be of more significant influence on structural design decision. Furthermore, the work presents requisite information modelling representations needed for bolting-on an object-oriented application to an existing BIM platform. It applied the feature mapping and extraction approach to select relevant building elements for sustainability analysis to be performed. It demonstrates that a number of $\mathrm{nD}$ building performance measures other than sustainability could be bolted-on to existing BIM-enabled platforms using API implementation. This means that in the near future, as the scope of BIM becomes clearer, researchers will be able to use similar principles to implement needed BIM extensions.

Besides the scope issues discussed in Section 3.1, it is worth mentioning that the prototype is a demonstration of concept and has certain limitations in application of typical real-world design scenarios. Firstly, the prototype depends on Revit BIM platform and may need to be reconfigured to operate on other platforms. Secondly, it is limited to steel-framed building to define achievable scope but has room for expansion to other structural framing systems and also professional domains. Thirdly, only rectangularshaped building can be considered but not limited on number of floors. 
A.H. Oti, W. Tizani, F.H. Abanda, A. Jaly-Zada, J.H.M. Tah. 2016. Structural sustainability appraisal in BIM, Automation in Construction, 69, September 2016, Pages 44-58 http://dx.doi.org/10.1016/j.autcon.2016.05.019

Table 5: BREEAM ratings and relevance to prototype

\begin{tabular}{|c|c|c|c|c|}
\hline BREEAM Section & Main Issues ( credits) & Weighting & $\begin{array}{c}\text { Weighting } \\
(\%)\end{array}$ & $\begin{array}{l}\text { Relevance to } \\
\text { prototype (\%) }\end{array}$ \\
\hline Management & $\begin{array}{l}\text { Commissioning } \\
\text { Construction site impacts } \\
\text { Security }\end{array}$ & 0.120 & 10.91 & \\
\hline Health \& Wellbeing & $\begin{array}{l}\text { Daylight, Lighting } \\
\text { Occupant thermal comfort } \\
\text { Acoustics } \\
\text { Indoor air and water quality }\end{array}$ & 0.150 & 13.64 & \\
\hline Energy & $\begin{array}{l}\mathrm{CO}_{2} \text { emissions (15) } \\
\text { Low or zero carbon technologies ( } 3 \text { ) } \\
\text { Energy sub metering (2) } \\
\text { Energy efficient building systems (4) }\end{array}$ & 0.190 & 17.27 & 10.80 \\
\hline Transport & $\begin{array}{l}\text { Public transport network connectivity } \\
\text { Pedestrian and Cyclist facilities } \\
\text { Access to amenities } \\
\text { Travel Plans }\end{array}$ & 0.080 & 7.27 & \\
\hline Water & $\begin{array}{l}\text { Water consumption } \\
\text { Leak detection } \\
\text { Water re-use and recycling }\end{array}$ & 0.060 & 5.45 & \\
\hline Materials & $\begin{array}{l}\text { Embodied life cycle impact - } \\
\text { materials } \\
\text { Materials re-use, landscape protection } \\
\text { Responsible sourcing \& Insulation } \\
\text { Robustness }\end{array}$ & 0.125 & 11.36 & 7.95 \\
\hline Waste & $\begin{array}{l}\text { Construction waste } \\
\text { Recycled aggregates } \\
\text { Recycling facilities }\end{array}$ & 0.075 & 6.82 & \\
\hline Land Use \& Ecology & $\begin{array}{l}\text { Site Selection } \\
\text { Protection of ecological features } \\
\text { Mitigation/ enhancement of eco. } \\
\text { value } \\
\text { Long term Biodiversity }\end{array}$ & 0.100 & 9.09 & 7.27 \\
\hline Pollution & $\begin{array}{l}\text { Refrigerant use and leakage } \\
\text { flood risk } \\
\mathrm{NO}_{\mathrm{x}} \text { emissions } \\
\text { Watercourse pollution } \\
\text { External light and noise pollution }\end{array}$ & 0.100 & 9.09 & \\
\hline Innovation & $\begin{array}{l}\text { Exemplary performance levels } \\
\text { Use of BREEAM Accredited } \\
\text { professionals } \\
\text { New Tech. and building processes }\end{array}$ & 0.100 & 9.09 & \\
\hline TOTAL & & 1.10 & 100 & 26.02 \\
\hline
\end{tabular}




\section{Conclusions}

This paper reviewed works that utilized API software facility to achieve add-in extensions in existing BIM enabled tools. It presented a proposed BIM extension that provides decision support for assessing the sustainability measures of structural solutions. The proposed extension encompasses a modelling framework, based on feature modelling technique to help structural engineers assess the alternative conceptual design options of steel-framed buildings. The framework combines three key sustainability indicators, LCC, carbon footprint and ecological footprint measures to assess the sustainability of buildings. LCC accounts for economic sustainability while carbon footprint and ecological footprint give a measure of the impact on the atmosphere and biosphere, respectively, of the environment. This work provides an extension for the scope of BIM in the area of structural sustainability appraisal. In this paper, we presented the operations and results of the proposed prototype system in assessing the sustainability credentials of alternative structural design solutions. The system visually provides the desirability scores of solutions on multi-criteria decision analysis basis which can aid designers in making design decisions. It makes it therefore possible for structural designer to consider sustainability, in the form of relative desirability scores, as additional criteria for favouring a particular design solution above alternatives. Although the research was targeted at sustainability in structural engineering domain, the approach can be used to tackle other $\mathrm{nD}$ modelling issues as may be applicable to other professional domains in the industry. Many researchers have tackled specific needs in the industry by using such BIM-enabled tools as parent programmes and test-beds for developing add-in extensions to demonstrate conceived concepts. The advantage being that programmes will not need to be developed from the scratch and it encourages researchers to focus on solving specific challenges in the construction sector. Also, it encourages the rapid development of programmes and eventually, the speedy expansion/maturity of BIM depending on how novel works and findings are managed.

Thus, API implementation is one of the software development kits available to enhance the rapid development of computer-based programmes. It can be adapted to different computer operating systems and has the benefit of allowing compiled codes to function without effecting any change to the system and the underlying codes that implements the API. As such software platforms can serve as test-bed for rapid application prototyping development which can lead to the rapid increase in contributions to the much needed BIM expansion. Current challenges such as the lack of dynamic parametric modelling of transactions between BIM and sustainability assessment tools can be tackled through the API implementation approach. There is need, therefore, for software developers, industry and academia to manage API related systems and their implementation. Since BIM is hinged on the extent of computerized digitization of the building project, a lot depends on software developers. As such, it is important to promote the implementation of open standardized API in BIM-enable tools. The modelling of $\mathrm{nD}$ building performance measures can potentially benefit from BIM extension through API implementations. Sustainability is one such measure associated with buildings. For the structural engineer, recent design criteria have put great emphasis on the sustainability credentials as part of the traditional criteria of structural integrity, constructability and cost. This paper concludes that API implementations are needed for expanding the BIM scope. The demonstrated structural sustainability API implementation concept utilized process modelling techniques, algorithms and object-based instantiations which could be useful in modelling other building performance measures of a building.

\section{References}

1. C. Cruz, Building Information Modeling, in A report of LAB. Le2i, 2008, Université de Bourgogne.

2. NIBS, National Building Information, Modeling Standards Part-1: Overview, Principles and Methodologies, 2007, US National Institute of Building Sciences Facilities Information Council, BIM Committee.

3. A. Lee, S. Wu, G. Aouad, nD modelling: the background in Constructing the future: $n$ D modelling, G. Aouad, A. Lee, and S. Wu, Editors. 2006, Taylor and Francis.

4. G. Aouad, A. Lee, S. Wu, Constructing the future: nD modelling. 2006: Taylor \& Francis Group.

5. A.H. Oti, W. Tizani, BIM extension for the sustainability appraisal of conceptual steel design. Advanced Engineering Informatics, 2015. 29(1): p. 28-46. 
6. T. Nguyen, T. Shehab, Z. Gao, Evaluating Sustainability of Architectural Designs Using Building Information Modeling. Open Construction and Building Technology Journal, 2010. 4: p. 1-8.

7. U. Rüppel, K. Schatz, Designing a BIM-based serious game for fire safety evacuation simulations. Advanced Engineering Informatics, 2011. 25(4): p. 600-611.

8. W. Maner. Rapid application development using iterative protyping. 1997 [cited October 2012]. Available from: http://csweb.cs.bgsu.edu/maner/domains/RAD.gif

9. D. Benslimane, S. Dustdar, A. Sheth, Services mashups: The new generation of web applications. Internet Computing, IEEE, 2008. 12(5): p. 13-15.

10. B.P. Rimal, A. Jukan, D. Katsaros, Y. Goeleven, Architectural requirements for cloud computing systems: an enterprise cloud approach. Journal of Grid Computing, 2011. 9(1): p. 3-26.

11. Y. Jiao, S. Zhang, Y. Li, Y. Wang, B. Yang, Towards cloud Augmented Reality for construction application by BIM and SNS integration. Automation in Construction, 2013. 33: p. 37-47.

12. A. Redmond, A. Hore, M. Alshawi, R. West, Exploring how information exchanges can be enhanced through Cloud BIM Automation in Construction, 2012. 24: p. 175-183.

13. E. Woollacott. APIs can't be copyrighted, says judge in Oracle case. 2012 [cited August 2013]. Available from: http://www.tgdaily.com/business-and-law-features/63756-apis-cant-be-copyrighted-says-judge-in-oraclecase\#JrWZ3H1JZE2u0dfv.99

14. B. Buck, J.K. Hollingsworth, An API for runtime code patching. International Journal of High Performance Computing Applications, 2000. 14(4): p. 317-329.

15. M.K. Zamanian, J.H. Pittman, A software industry perspective on AEC information models for distributed collaboration. Automation in Construction, 1999. 8(3): p. 237-248.

16. S. Boddy, Y. Rezgui, G. Cooper, M. Wetherill, Computer integrated construction: A review and proposals for future direction. Advances in engineering software, 2007. 38(10): p. 677-687.

17. M. Nour, K. Beucke, An open platform for processing IFC model versions. Tsinghua Science \& Technology, 2008. 13: p. 126-131.

18. M.P. Nepal, S. Staub-French, R. Pottinger, J. Zhang, Ontology-based feature modeling for construction information extraction from a building information model. Journal of Computing in Civil Engineering, 2012. 27(5): p. 555-569.

19. J.C. Cheng, L.Y. Ma, A BIM-based system for demolition and renovation waste estimation and planning. Waste Management, 2013. 33(6): p. 1539-1551.

20. J. Wang, J. Li, X. Chen. Parametric design based on building information modeling for sustainable buildings. in International Conference on Challenges in Environmental Science and Computer Engineering (CESCE) 2010. IEEE. DOI: 10.1109/CESCE.2010.285.

21. W. Yan, C. Culp, R. Graf, Integrating BIM and gaming for real-time interactive architectural visualization. Automation in Construction, 2011. 20(4): p. 446-458.

22. W. Yan, M. Clayton, J. Haberl, W. Jeong, J.B. Kim, S. Kota, J.L.B. Alcocer, M. Dixit. Interfacing BIM with Building Thermal and Daylighting Modeling. in Proceedings of the 13th International Conference of the International Building Performance Simulation Association (IBPSA'13), 25-30 August, 2013. E. Wurtz (Editor). Chambery, France.

23. S. Zhang, J. Teizer, J.-K. Lee, C.M. Eastman, M. Venugopal, Building information modeling (BIM) and safety: Automatic safety checking of construction models and schedules. Automation in Construction, 2013. 29: p. 183-195.

24. J. Irizarry, E.P. Karan, F. Jalaei, Integrating BIM and GIS to improve the visual monitoring of construction supply chain management. Automation in Construction, 2013. 31: p. 241-254.

25. H.-T. Chen, S.-W. Wu, S.-H. Hsieh, Visualization of CCTV coverage in public building space using BIM technology. Visualization in Engineering, 2013. 1(1): p. 1-17.

26. L.C. Bank, B.P. Thompson, M. McCarthy, Decision-making tools for evaluating the impact of materials selection on the carbon footprint of buildings. Carbon Management, 2011. 2(4): p. 431-441.

27. G. Vilkner, C. Wodzicki, E. Hatfield, T. Scarangello. Integrated Processes in Structural Engineering. in New Horizons and Better Practices, 2007. ASCE. p. 1-10. DOI: doi: 10.1061/40946(248)50.

28. Y.-C. Lin, Y.-C. Su, Developing Mobile-and BIM-Based Integrated Visual Facility Maintenance Management System. The Scientific World Journal, 2013. 2013: p. 10.

29. A.Y. Chen, T. Huang. BIM-Enabled Decision Making for In-Building Rescue Missions. in Computing in Civil and Building Engineering, 2014. ASCE. p. 121-128. DOI: 10.1061/9780784413616.016.

30. S. Kota, J.S. Haberl, M.J. Clayton, W. Yan, Building Information Modeling (BIM)-based daylighting simulation and analysis. Energy and Buildings, 2014. 81: p. 391-403.

31. S.-P. Ho, H.-P. Tserng, S.-H. Jan, Enhancing Knowledge Sharing Management Using BIM Technology in Construction. The Scientific World Journal, 2013. 2013: p. 10.

32. R. de Laat, L. van Berlo, Integration of BIM and GIS: The development of the CityGML GeoBIM extension, in Advances in 3D Geo-Information Sciences. 2011, Springer. p. 211-225. DOI: 10.1007/978-3-642-12670-3_13. 
33. A. Jaly zada, W. Tizani, A. Oti. Building Information Modelling (BIM)—Versioning for Collaborative Design. in Computing in Civil and Building Engineering, 2014. ASCE. p. 512-519. DOI: 10.1061/9780784413616.064.

34. J. Elkington, Partnerships from cannibals with forks: The triple bottom line of 21 st century business. Environmental Quality Management, 1998. 8(1): p. 37-51.

35. WECD, Our common future, 1987, World Commission on Environment and Development (WCED).

36. J. Fiksel, Designing resilient, sustainable systems. Environmental science \& technology, 2003. 37(23): p. 5330-5339.

37. G. Finnveden, M.Z. Hauschild, T. Ekvall, J. Guinee, R. Heijungs, S. Hellweg, A. Koehler, D. Pennington, S. Suh, Recent developments in life cycle assessment. Journal of Environmental Management, 2009. 91(1): p. 1-21.

38. T. Maver, J. Petric, Sustainability: real and/or virtual? Automation in Construction, 2003. 12(6): p. 641-648.

39. G.K.C. Ding, Sustainable construction-role of environmental assessment tools. Environment and Management, 2008. 86: p. 451-464.

40. F.H. Abanda, J.H. Tah, D. Duce, PV-TONS: A photovoltaic technology ontology system for the design of PV-systems. Engineering Applications of Artificial Intelligence, 2013. 26(4): p. 1399-1412.

41. U. Berardi, Sustainability assessment in the construction sector: rating systems and rated buildings. Sustainable Development, 2012. 20(6): p. 411-424.

42. A. Haapio, P. Viitaniemi, A critical review of building environmental assessment tools. Environmental impact assessment review, 2008. 28(7): p. 469-482.

43. ISO 15392, Sustainability in Building Construction - General Principles, 2008.

44. BS EN 15643-1, Sustainability of construction works - Sustainability assessment of buildings: General framework, 2010, British Standard.

45. J.A. Todd, D. Crawley, S. Geissler, G. Lindsey, Comparative assessment of environmental performance tools and the role of Green Building Challenge. Building Research \& Information, 2001. 29(5): p. 324-335

46. N. Kohler, S. Moffatt, Life cycle analysis of the built environment, in Industry and Environment. 2003, UNEP. p. 17-21.

47. A. Lee, M. Sexton, nD modelling: industry uptake considerations. Construction Innovation: Information, Process, Management, 2007. 7(3): p. 288-302.

48. C. Eastman, P. Teicholz, R. Sacks, BIM Handbook: A guide to Building Information Modelling for Owners, Manager, Designers, Engineers, and Contractors. 2008, USA: John Wiley \& Sons, Inc.

49. J.H.M. Tah, W. Zhou, F.H. Abanda, F.K.T. Cheung. Towards a holistic modeling framework for embodied carbon and waste in the building lifecycle. in Proceedings of the International Conference on Computing in Civil and Building Engineering, 30 June-2 July, 2010. W. Tizani (Editor). Nottingham, UK: University of Nottingham Press

50. B. Nuseibeh, S. Easterbrook. Requirements engineering: a roadmap. in Proceedings of the Conference on The Future of Software Engineering, June 04 - 11, 2000. Limerick, Ireland: ACM. DOI: http://doi.acm.org/10.1145/336512.336523.

51. P. Svanerudh, Design support system for multi-storey timber structures, 2001, Lulea Tekniska Universitet.

52. J.P. Van Leeuwen, H. Wagter. Architectural design-by-Features. in Proceedings of the 7th International Conference on Computer Aided Architectural Design Futures held in Munich, Germany, 1997. R. Junge (Editor): Kluwer Academic Publishers, Dordrecht. DOI: 10.1007/978-94-011-5576-2_7.

53. S. Staub-French, M.P. Nepal, Reasoning about component similarity in building product models from the construction perspective. Automation in Construction, 2007. 17(1): p. 11-21.

54. A.H. Oti, W. Tizani. A sustainability extension for building information modelling in Proceedings of the CIB W78 2012 : 29th International Conference -Beirut, Lebanon, 17-19 October, 2012. R.R. Issa (Editor). Beirut, Lebanon: CIB MENA.

55. A.H. Oti, W. Tizani. A Sustainability Appraisal Framework for the Design of Steel-Framed Buildings. in Proceedings of the Thirteenth International Conference on Civil, Structural and Environmental Engineering Computing, 2011. B.H.V. Topping and Y. Tsompanakis (Editors). Crete, Greece: Civil-Comp Press, Stirlingshire, United Kingdom,.

56. S.C. Kaethner, J.A. Burridge, Embodied CO2 of structural frames. The Structural Engineer, 2012. 90(5): p. 33-40.

57. A. Sarja, Integrated life cycle design of structures. 2002: Spon Press, Taylor and Francis Group, London.

58. K. Sarma, H. Adeli, Life cycle cost optimization of steel structures. International Journal for Numerical Methods in Engineering, 2002. 55(12): p. 1451-1462.

59. Autodesk, Develpoers's Guide -Version 1.0, 2010, Autodesk Inc.

60. P.J. Deitel, H.M. Deitel, C\# 2008 for Programmers: Deitel Developer Series. 2008: Prentice Hall.

61. D. Zowghi, C. Coulin, Requirements elicitation: A survey of techniques, approaches, and tools, in Engineering and managing software requirements. 2005, Springer. p. 19-46.

62. P. Geyer, M. Buchholz, Parametric systems modeling for sustainable energy and resource flows in buildings and their urban environment. Automation in Construction, 2012. 22: p. 70-80.

63. O. Ugwu, M. Kumaraswamy, F. Kung, S. Ng, Object-oriented framework for durability assessment and life cycle costing of highway bridges. Automation in Construction, 2005. 14(5): p. 611-632. 
A.H. Oti, W. Tizani, F.H. Abanda, A. Jaly-Zada, J.H.M. Tah. 2016. Structural sustainability appraisal in BIM, Automation in Construction, 69, September 2016, Pages 44-58 http://dx.doi.org/10.1016/j.autcon.2016.05.019

64. S. Yeo, M. Mak, S. Balon, Analysis of decision-making methodologies for desirability score of conceptual design. Journal of Engineering Design, 2004. 15(2): p. 195-208.

65. D. Langdon, ed. SPON's Civil Engineering and Highway Works Price Book 26th ed. 2012, SPON Press.

66. G. Hammond, C. Jones, Inventory of Carbon \& Energy (ICE) Version 2.0, Sustainable Energy Research Team (SERT) University of Bath, 2011: Bath.

67. M.R. Asl, S. Zarrinmehr, M. Bergin, W. Yan, BPOpt: A framework for BIM-based performance optimization. Energy and Buildings, 2015. 108: p. 401-412.

68. E. Giovannini, Handbook on constructing composite indicators: methodology and user guide, 2008, OECD.

69. A. Galli, T. Wiedmann, E. Ercin, D. Knoblauch, B. Ewing, S. Giljum, Integrating Ecological, Carbon and Water footprint into a "Footprint Family" of indicators: Definition and role in tracking human pressure on the planet. Ecological Indicators, 2012. 16: p. 100-112.

70. B.C. Lippiatt, A.S. Boyles, Using BEES to select cost-effective green products. The International Journal of Life Cycle Assessment, 2001. 6(2): p. 76-80.

71. BRE, Scheme Document SD 5055 -BREEAM Offices 2008 2012, Building Research Establishment (BRE) Group.

72. R.J. Cole, Building environmental assessment methods: redefining intentions and roles. Building Research \& Information, 2005. 33(5): p. 455-467.

73. R.J. Cole, Building environmental assessment methods: clarifying intentions. Building Research \& Information, 1999. 27(45): p. 230-246. 